\title{
A mechanistic modelling and data assimilation approach to estimate the carbon/chlorophyll and carbon/nitrogen ratios in a coupled hydrodynamical-biological model
}

\author{
B. Faugeras ${ }^{1}$, O. Bernard ${ }^{2}$, A. Sciandra ${ }^{3}$, and M. Lévy ${ }^{4}$ \\ ${ }^{1}$ Institut de Recherche pour le Développement (IRD), Sète, France \\ ${ }^{2}$ Institut National de Recherche en Informatique et Automatique (INRIA), COMORE project, Sophia-Antipolis, France \\ ${ }^{3}$ Laboratoire d'Océanographie de Villefranche-sur-mer (LOV), CNRS, Villefranche-sur-mer, France \\ ${ }^{4}$ Laboratoire d'Océanographie Dynamique et de Climatologie (LODYC), CNRS, Paris, France
}

Received: 19 July 2004 - Revised: 6 November 2004 - Accepted: 8 November 2004 - Published: 12 November 2004

\begin{abstract}
The principal objective of hydrodynamicalbiological models is to provide estimates of the main carbon fluxes such as total and export oceanic production. These models are nitrogen based, that is to say that the variables are expressed in terms of their nitrogen content. Moreover models are calibrated using chlorophyll data sets. Therefore carbon to chlorophyll $(\mathrm{C}: \mathrm{Chl})$ and carbon to nitrogen $(\mathrm{C}: \mathrm{N})$ ratios have to be assumed. This paper addresses the problem of the representation of these ratios. In a 1D framework at the DYFAMED station (NW Mediterranean Sea) we propose a model which enables the estimation of the basic biogeochemical fluxes and in which the spatio-temporal variability of the $\mathrm{C}: \mathrm{Chl}$ and $\mathrm{C}: \mathrm{N}$ ratios is fully represented in a mechanical way. This is achieved through the introduction of new state variables coming from the embedding of a phytoplankton growth model in a more classical Redfieldian NNPZD-DOM model (in which the C:N ratio is assumed to be a constant). Following this modelling step, the parameters of the model are estimated using the adjoint data assimilation method which enables the assimilation of chlorophyll and nitrate data sets collected at DYFAMED in 1997.

Comparing the predictions of the new Mechanistic model with those of the classical Redfieldian NNPZD-DOM model which was calibrated with the same data sets, we find that both models reproduce the reference data in a comparable manner. Both fluxes and stocks can be equally well predicted by either model. However if the models are coinciding on an average basis, they are diverging from a variability prediction point of view. In the Mechanistic model biology adapts much faster to its environment giving rise to higher short term variations. Moreover the seasonal variability in total production differs from the Redfieldian NNPZD-DOM model to the Mechanistic model. In summer the Mechanistic
\end{abstract}

Correspondence to: B. Faugeras

(blaise.faugeras@ifremer.fr) model predicts higher production values in carbon unit than the Redfieldian NNPZD-DOM model. In winter the contrary holds.

\section{Introduction}

The estimation of the amount of carbon fixed by oceanic phytoplankton during primary production is a key point to quantify the future evolution of atmospheric carbon. To address this issue biogeochemical models are increasingly being used and applied to a variety of regions in the ocean. Most of these models are more or less complex variants of the Fasham et al. (1990) model and are nitrogen based. That is to say that the compartments or state variables of the model, and in particular phytoplankton, are expressed in terms of their nitrogen content $\left(\mathrm{mmolN} / \mathrm{m}^{3}\right)$. The main reason for this is that nitrogen plays a critical role in ocean biology as an important limiting nutrient in a wide range of areas. Therefore it is a natural currency for modelling biological fluxes.

However, if the aim of such a model is to estimate and predict carbon fluxes, then carbon to nitrogen ratios have to be assumed. It is therefore quite common to use the Redfield ratio to convert the nitrogen fluxes computed from the phytoplankton compartment to carbon fluxes. However the nitrogen to carbon ratio is known to be highly variable (Droop, 1968; Bury et al., 2001) both in time and space.

A second weakness of the classical approach is due to the lack of available measurements to calibrate and validate the model. Since the nitrogen of the phytoplanktonic compartment cannot be measured, the chlorophyll $a$ measurements are broadly used to assess the behaviour of this compartment. Therefore a nitrogen to chlorophyll ratio has to be assumed, or using the $\mathrm{C}: \mathrm{N}$ already hypothesised, a C:Chl must be supposed. In most simple models this ratio is assumed 

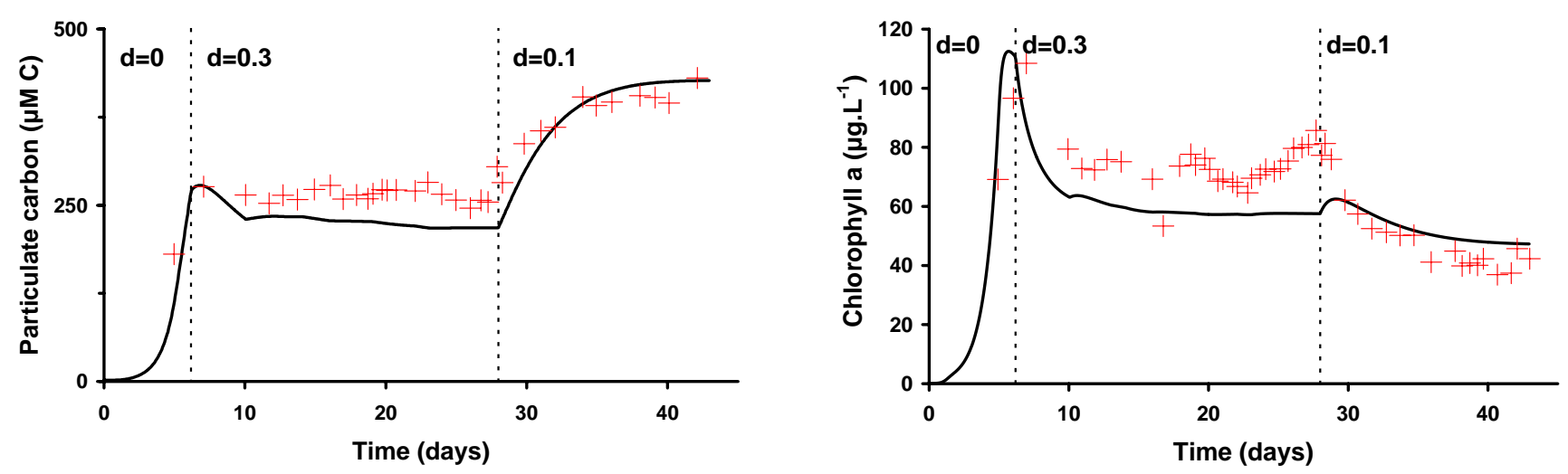

Fig. 1. Comparison of experimental data in chemostat with Rhodomonas salina (Cryptophyceae) and the BIOLOV model output for particular carbon (left) and chlorophyll (right). The dilution rate is successively set to $0,0.3$ and $0.1 \mathrm{~d}^{-1}$. From Pawlowski et al. (2002).

to be constant (Fasham et al., 1990), and in more detailed approaches it can be represented as a static function of light and nitrogen (Doney et al., 1996; Lévy et al., 1998). From laboratory studies it was demonstrated that the $\mathrm{C}: \mathrm{Chl}$ is also highly variable, especially in conditions of nitrogen limitation (Rhee and Gothan, 1981; Sciandra et al., 1997). In the end, the biochemical models which take explicitly into account the physiological plasticity of the phytoplankton are rather scarce (Lefevre et al., 2003).

Then the main question that we want to address in this paper rises. What are the effect of the variability of the C:N and $\mathrm{C}: \mathrm{Chl}$ ratio on the predictions of the biogeochemical models and on their calibration? What is the benefit of complexifying the model by predicting these ratio with a Mechanistic model integrating the phenomenon of coupling between light and nitrogen limitation?

The goal of this paper is to address this aspect using a coupled hydrodynamical-biological modelling. This work follows another study where only the spatial variability of the C:Chl was considered (Faugeras et al., 2003), and was estimated through an assimilation step. Here we consider the same 1D framework at the DYFAMED station, we propose a model which enables the estimation of the basic biogeochemical fluxes and in which the spatio-temporal variability of the $\mathrm{C}: \mathrm{Chl}$ and $\mathrm{C}: \mathrm{N}$ ratios is fully represented in a mechanical way.

This is achieved through the use of a new biological model (the BIOLOV model Pawlowski et al., 2002; Pawlowski, 2004)) developed and validated in chemostat experiments. This phytoplanktonic model describes independently the behaviour of phytoplanktonic carbon $C$, nitrogen $N$ and chlorophyll $L$. It is an alternative to other existing models, like the model presented in Geider et al. (1997) or in Baumert (1996). Note that other more complicated phytoplankton growth models predicting the behaviour of these variables could be used (Zonneveld, 1998; Flynn, 2001), but their higher complexity make them much more difficult to integrate in the framework of a biogeochemical model. Figure 1 demonstrates the ability of the BIOLOV model to reproduce, with a limited set of parameters, both the steady state val- ues and the transients for chemostat experiments with the Cryptophyceae Rhodomonas salina. The considered coupled hydrodynamical-biological model thus results from the embedding of this BIOLOV phytoplankton growth model, in a 1D Redfieldian NNPZD-DOM model (Nitrate, Ammonium, Phytoplankton, Zooplankton Detritus, Dissolved Organic Matter) already validated at DYFAMED under constant and fluctuating experimental conditions.

The objective of this paper is not to fully compare this "classical" 1D Redfieldian NNPZD-DOM model with our new model in terms of the quality of the simulated most important biogeochemical fluxes such as production and export. Actually this would have been an interesting question to address but as shown in Faugeras et al. (2003) production and export fluxes estimates can not be recovered at DYFAMED from stock (chlorophyll and nitrate) data. Indeed they have shown that some measurements of these fluxes need to be included in the assimilation process in order to constrain parameter estimation and to guaranty consistent predictions. As a consequence both models produce comparable average fluxes values since these are constrained by data assimilation. Therefore we clearly concentrate on the spatial and temporal variability of the fluxes and ratios as predicted by the models. Then we estimate the benefit of using more complicated models if we want to account both the average value and the variability of these quantities.

There are several reasons why the DYFAMED station, located in the Northwestern Mediterranean Sea, is an interesting test case. First, several biogeochemical production regimes that take place in the world ocean are found here. Deep convection occurs during winter, leading to a spring bloom. Oligotrophy prevails during summer while perturbations in the meteorological forcing generate a secondary bloom in fall. Secondly, the station is far enough away from the Ligurian Current to be sufficiently protected from lateral transport, thereby permitting a 1D study (Marty, 1993). Moreover, DYFAMED is a JGOFS time-series station which means that a data base of biogeochemical and physical parameters is available to carry out and validate simulations. A final reason for using the DYFAMED station is that it is 

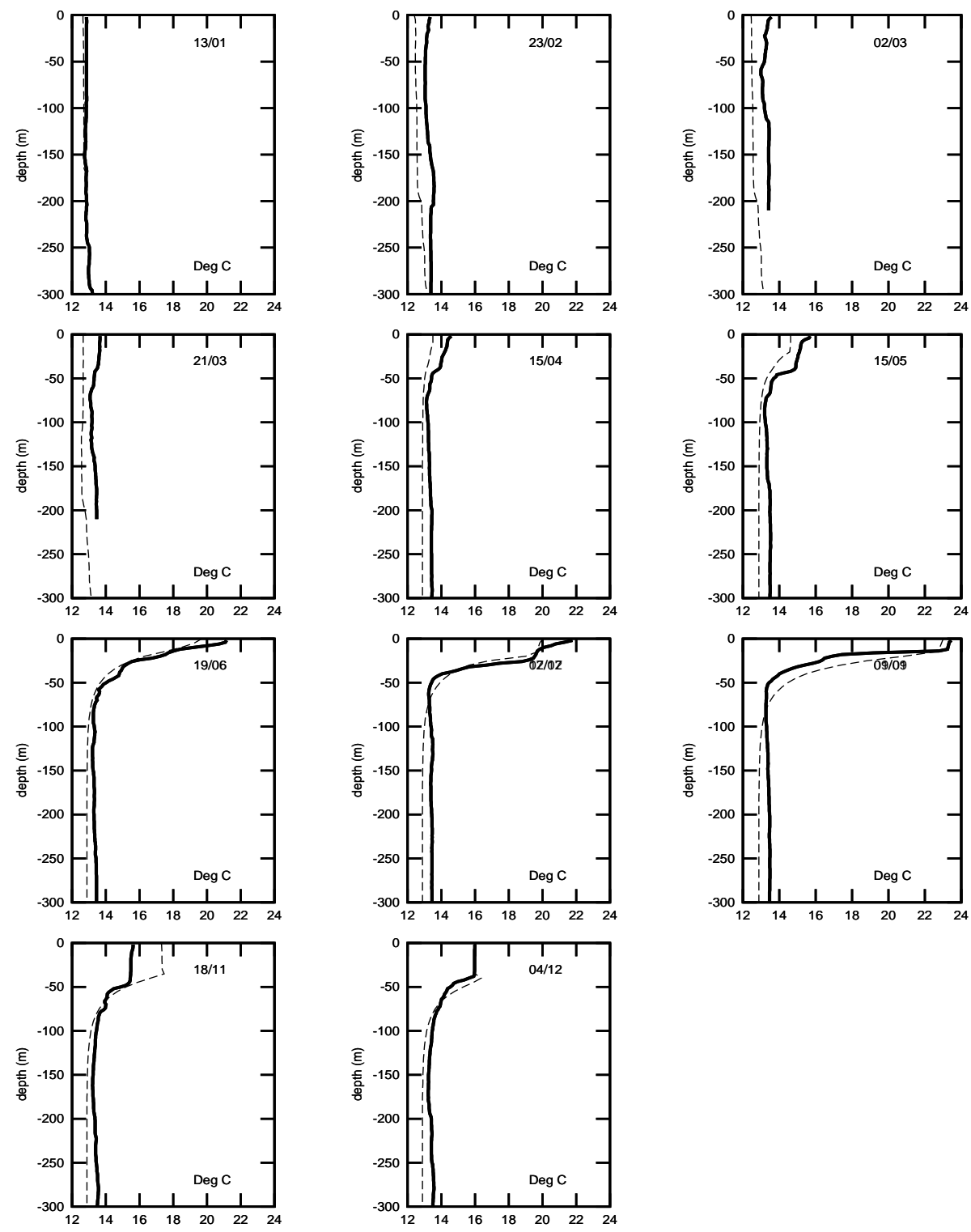

Fig. 2. Temperature profiles. Model results vs. data collected at DYFAMED in 1997; solid line: data; dashed line: simulation.

relatively well known (Deep-Sea Res. II, special issue, 49, 11, 2002), and has been the subject of previous model studies (Lévy et al., 1998; Mémery et al., 2002; Faugeras et al., 2003).

The paper is organized as follows: Sect. 2 is devoted to the construction of the new model by embedding the BIOLOV model into the 1D Redfieldian NNPZD-DOM model. In all this paper the Redfieldian NNPZD-DOM model is also simply referred to as "the Redfieldian model" or "the NNPZDDOM model", and the new proposed model is referred to as "the Mechanistic model".

Section 3 discusses the calibration of the Mechanistic model using data assimilation. Numerical results are presented in Sect. 4 and a Discussion section ends the paper.

\section{Model presentation}

\subsection{A one-dimensional NNPZD-DOM model}

The main goal of this section is to briefly present the onedimensional NNPZD-DOM biological model proposed in Mémery et al. (2002), originally qualitatively calibrated for DYFAMED and then used to assimilate data from this station in Faugeras et al. (2003). This model is one of the two basis elements of the new model proposed in this paper and for sake of clarity we will recall a few elements about it. However, we refer to Mémery et al. (2002) and Lévy et al. (1998) for details of the different modelled processes and for the parameterizations used. Compared to other more complete models (Fasham et al., 1990; Spitz et al., 2001), the relative simplicity of this model is a trade-off to obtain a first approximation of the basic biogeochemical fluxes with a minimum 


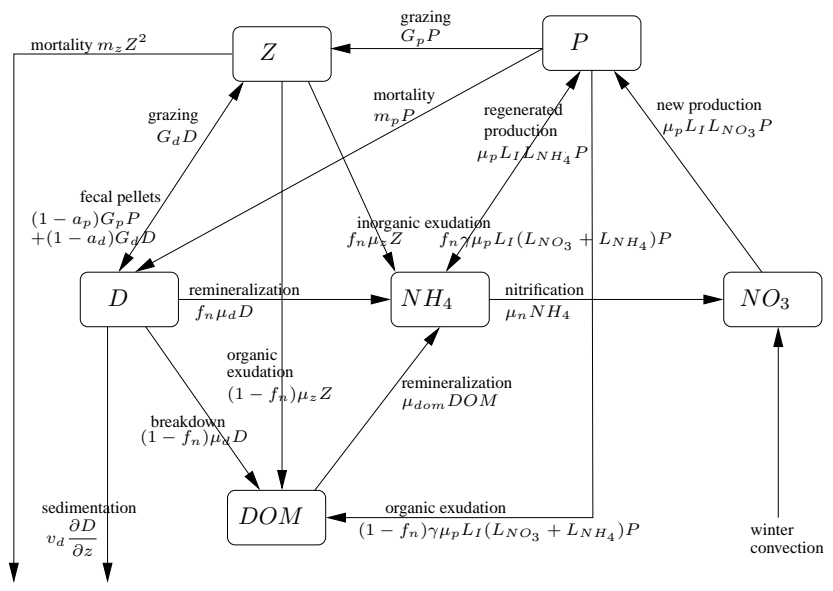

Fig. 3. Schematic representation of the compartments and processes of the NNPZD-DOM surface layer model.

number of prognostic variables. Nitrate and ammonium allow the estimation of new and regenerated production, zooplankton mortality and detrital sedimentation feed the particle export flux.

The biological model is embedded in a 1D physical model, which simulates the evolution over time of velocity, temperature, salinity and turbulent kinetic energy (TKE). Figure 2 shows temperature profiles (simulated profiles versus data which were used to calibrate the physical model). As for dynamical processes, the only one taken into account is vertical diffusion. The mixing coefficient, $K$, is obtained diagnostically from TKE, with a 1.5 closure scheme in the Mellor Yamada nomenclature (Gaspar et al., 1990). The model covers the first $400 \mathrm{~m}$ of the water column, with a vertical discretization of $5 \mathrm{~m}$.

Biological tracers are vertically mixed with the same diffusion coefficient as temperature and salinity. A specific biological reaction term, $F_{B}$, is added to the diffusion equation. Tracers are expressed in terms of their nitrogen contents $\left(\mathrm{mmolNm}{ }^{-3}\right)$. For each of the state variables, $\mathrm{NO}_{3}, \mathrm{NH}_{4}, P$, $Z, D$ and $D O M$, the prognostic equation reads as follows:

$\frac{\partial B}{\partial t}-\frac{\partial}{\partial z}\left(K \frac{\partial B}{\partial z}\right)=F_{B}$,

where $B$ is one of the state variables i.e. one of the biological tracer concentration. A schematic representation of the model is shown on Fig. 3 and the parameters are presented in Table 1.

The formulation of phytoplankton growth takes into account limitation by both nutrients and light. Following Hurtt and Armstrong (1996), a Michaelis-Menten function, $L_{\mathrm{NH}_{4}}$, is used to express limitation by ammonium:

$L_{\mathrm{NH}_{4}}=\frac{\mathrm{NH}_{4}}{k_{n}+\mathrm{NH}_{4}}$.

Based on the hypothesis that the total limitation, by both ammonium and nitrate, $L_{\mathrm{NO}_{3}}+L_{\mathrm{NH}_{4}}$, follows the same law,

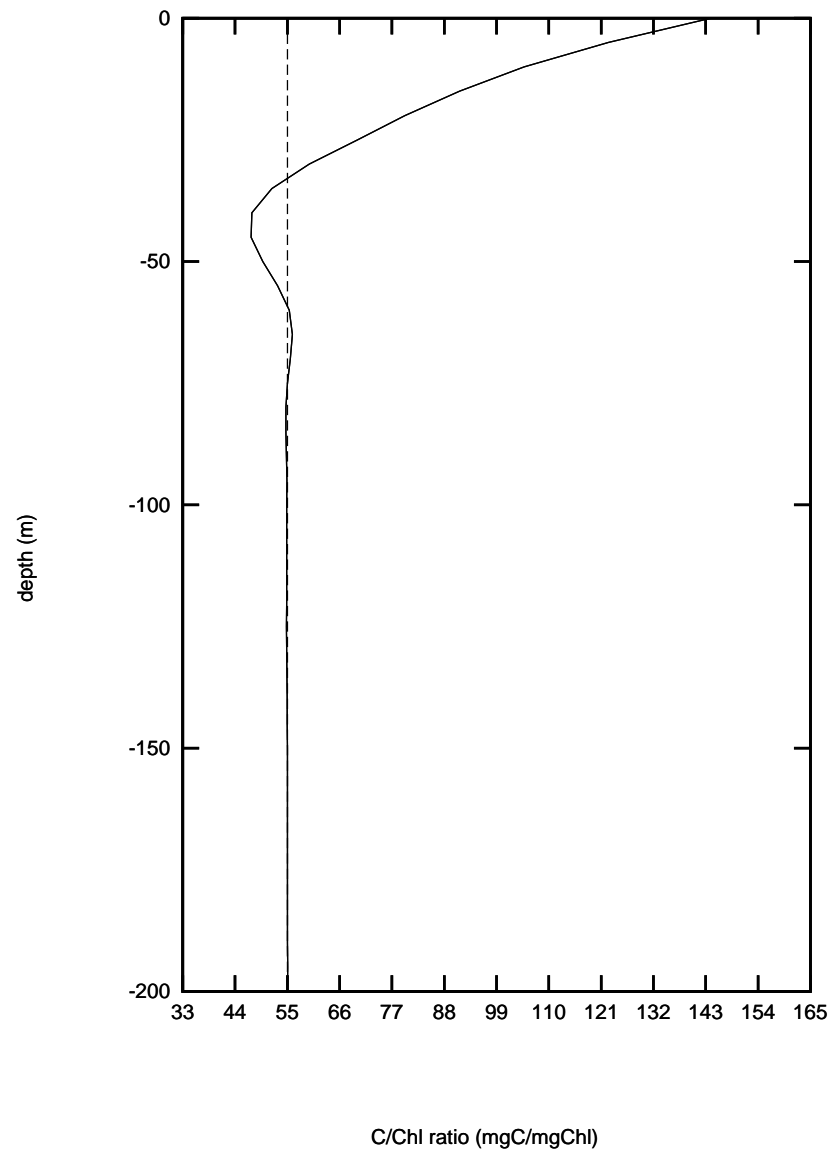

Fig. 4. Dashed line: first guess constant $\mathrm{C}: \mathrm{Chl}$ ratio. Continuous line: $\mathrm{C}: \mathrm{Chl}$ ratio allowing vertical variability estimated through the assimilation of the 1997 DYFAMED data set (from Faugeras et al., 2003). Also see Fig. 12 for a plot of this ratio as a function of light.

i.e.

$L_{\mathrm{NO}_{3}}+L_{\mathrm{NH}_{4}}=\frac{\mathrm{NO}_{3}+\mathrm{NH}_{4}}{\left(k_{n}+\mathrm{NO}_{3}+\mathrm{NH}_{4}\right)}$,

we obtain for the expression of limitation by nitrate,

$L_{\mathrm{NO}_{3}}=\frac{k_{n} \mathrm{NO}_{3}}{\left(k_{n}+\mathrm{NH}_{4}\right)\left(k_{n}+\mathrm{NO}_{3}+\mathrm{NH}_{4}\right)}$.

The function, $L_{I}$, representing limitation by light is expressed as follows:

$L_{I}=1-\exp \left(-I(z, P) / k_{\text {par }}\right)$.

The photosynthetic available radiation, $I(z, P)$, is predicted from surface irradiance and phytoplankton pigment content according to a simplified version of a light absorption model detailed in Morel (1988). Two different wavelengths corresponding to green and red are considered and the associated absorption coefficients, $k_{g}$ and $k_{r}$, depend on the local phytoplankton concentrations:

$k_{g}=k_{g o}+k_{g p}\left(\frac{12 P r_{d}}{r_{\mathrm{pig}} r_{c}}\right)^{l_{g}}$, 
Table 1. The 28 parameters of the NNPZD-DOM model (excluding the 20 parameters of the C:Chl profile).

\begin{tabular}{|c|c|c|c|}
\hline parameter & name & value & unit \\
\hline half-saturation const. for nutrients & $k_{n}$ & 0.01 & mmolN.m ${ }^{-3}$ \\
\hline carbon/chlorophyll ratio & $r_{c}$ & 55 & mgC.mgChla ${ }^{-1}$ \\
\hline phyto. exudation fraction & $\gamma$ & 0.05 & \\
\hline zoo. nominal preference for phyto food & $r$ & 0.7 & \\
\hline max. specific zoo. grazing rate & $g_{z}$ & $8.68 \mathrm{E}-6$ & $s^{-1}$ \\
\hline half-saturation const. for grazing & $k_{z}$ & 1 & mmolN.m ${ }^{-3}$ \\
\hline non-assimilated phyto. by zoo. & $a_{p}$ & 0.3 & \\
\hline non-assimilated detritus by zoo. & $a_{d}$ & 0.5 & \\
\hline zoo. specific exudation rate & $\mu_{z}$ & $1.16 \mathrm{E}-6$ & $\mathrm{~s}^{-1}$ \\
\hline phyto. mortality rate & $m_{p}$ & $9.027 \mathrm{E}-7$ & $\mathrm{~s}^{-1}$ \\
\hline zoo. mortality rate & $m_{z}$ & $1.0 \mathrm{E}-7$ & mmolN.m $\mathrm{m}^{-3} \cdot s^{-1}$ \\
\hline detritus breakdown rate & $\mu_{d}$ & $1.04 \mathrm{E}-6$ & $\mathrm{~s}^{-1}$ \\
\hline detritus sedimentation speed & $v_{d}$ & $5.8 \mathrm{E}-5$ & $\mathrm{~m} \cdot \mathrm{s}^{-1}$ \\
\hline max. phyto. growth rate & $\mu_{p}$ & $2.31 \mathrm{E}-5$ & $s^{-1}$ \\
\hline light half-saturation const. & $k_{p r}$ & 33.33 & W.m ${ }^{-2}$ \\
\hline decay rate below the euphotic layer & $\tau$ & $5.80 \mathrm{E}-5$ & $\mathrm{~s}^{-1}$ \\
\hline ratio of inorganic exudation & $f_{n}$ & 0.8 & \\
\hline nitrification rate & $\mu_{n}$ & $3.81 \mathrm{E}-7$ & $\mathrm{~s}^{-1}$ \\
\hline slow remineral. rate of $D O M$ to $\mathrm{NH}_{4}$ & $\mu_{d m}$ & $6.43 \mathrm{E}-8$ & $\mathrm{~s}^{-1}$ \\
\hline coeff. for Martin's remineralization profile & $h_{r}$ & -0.858 & \\
\hline pigment absorption in red & $k_{r p}$ & 0.037 & $\mathrm{~m}^{-1} \cdot\left(\mathrm{mgChl} . \mathrm{m}^{-3}\right)^{-l_{r}}$ \\
\hline pigment absorption in green & $k_{g p}$ & 0.074 & $\mathrm{~m}^{-1} \cdot\left(\mathrm{mgChl} \cdot \mathrm{m}^{-3}\right)^{-l_{g}}$ \\
\hline power law for absorption in red & $l_{r}$ & 0.629 & \\
\hline power law for absorption in green & $l_{g}$ & 0.674 & \\
\hline contribution of $\mathrm{Chl}$ to absorbing pigments & $\stackrel{\circ}{r_{\text {pig }}}$ & 0.7 & \\
\hline water absorption in green & $k_{\mathrm{go}}$ & 0.0232 & $\mathrm{~m}^{-1}$ \\
\hline water absorption in red & $k_{\mathrm{ro}}$ & 0.225 & $\mathrm{~m}^{-1}$ \\
\hline carbon/nitrogen ratio & $r_{d}$ & 6.625 & mmolC.mmolN ${ }^{-1}$ \\
\hline
\end{tabular}

$k_{r}=k_{r o}+k_{r p}\left(\frac{12 P r_{d}}{r_{\mathrm{pig}} r_{c}}\right)^{l_{r}}$.

Then $I(z, P)$ is written as the sum of the contribution from each of the two considered wave lengths:

$I(z, P)=I_{r}(z, P)+I_{g}(z, P)$.

Given an initial condition on the surface, $I(z=0)$ proportional to the solar flux and split equally into

$I_{g}(z=0)=I_{r}(z=0)=I(z=0) / 2$,

$I_{r}(z, P)$ and $I_{g}(z, P)$ are computed recursively according to the following absorption equations:

$I_{g}(z, P)=I_{g}(z-\Delta z, P)\left(1-\exp \left(-k_{g} \Delta z\right)\right)$,

$I_{r}(z, P)=I_{r}(z-\Delta z, P)\left(1-\exp \left(-k_{r} \Delta z\right)\right)$,

where $\Delta z$ is the space discretization step along the water column.

Grazing of phytoplankton and detritus is formulated following Fasham et al. (1990):

$G_{p}=G_{p}(P, Z, D)=\frac{g_{z} r P Z}{k_{z}(r P+(1-r) D)+r P^{2}+(1-r) D^{2}}$,
$G_{d}=G_{d}(P, Z, D)=\frac{g_{z}(1-r) D Z}{k_{z}(r P+(1-r) D)+r P^{2}+(1-r) D^{2}}$.

Other modelled biogeochemical interactions include phytoplankton mortality, phytoplankton exudation, zooplankton mortality (considered as large particles which are supposed to be instantaneously exported below the productive layer and remineralized in the water column), zooplankton exudation, fecal pellet production, detritus sedimentation, detritus breakdown, nitrification, and dissolved organic matter remineralization (Fig. 3).

Below a depth of $150 \mathrm{~m}$, remineralization processes are preponderant and the surface model does not apply. Instead, decay of phytoplankton, zooplankton and detritus in nutrients with a rate $\tau$, and a vertical redistribution of zooplankton mortality according to Martin's profile (Martin and Fitzwater, 1992) parameterize remineralization below the surface layer. This parameterization conserves total nitrogen.

An important point in the formulation of this NNPZDDOM model concerns the $\mathrm{C}: \mathrm{Chl}$ ratio, $r_{c}$. It is a parameter which enters the model through the light limitation term $L_{I}$ (Eqs. 6 and 7). It is used to convert phytoplankton $P$ into Chl which is one of the measured quantity to which the model's output can be compared. The simplest way to 


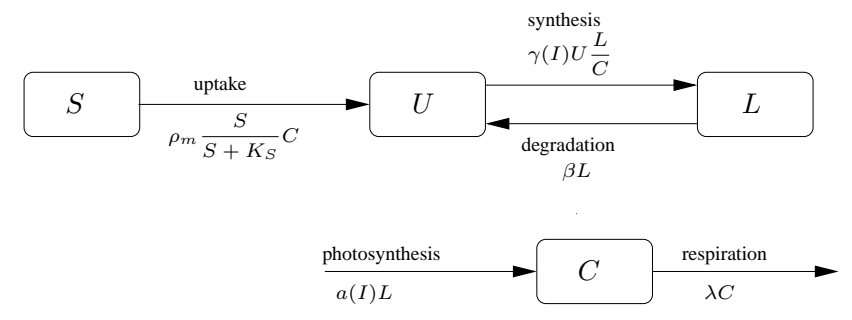

Fig. 5. Schematic representation of the compartments and processes of the BIOLOV model.

choose $r_{c}$ is to take a constant (in space and time) value. However as with earlier studies, (Geider et al., 1997), it is quantitatively shown in Faugeras et al. (2003) assimilating data from the DYFAMED station that it is impossible to simulate a correct surface chlorophyll bloom intensity together with a correct summer subsurface chlorophyll maximum in an oligotrophic regime using this constant $\mathrm{C}: \mathrm{Chl}$ ratio. This is also in agreement with experimental observations showing a large increase of the $\mathrm{C}: \mathrm{Chl}$ ratio with respect to light (Cullen, 1990; Chalup and Laws, 1990). To overcome this difficulty the authors gave a vertical variability to this ratio (Fig. 4). This lead to a significant improvement of the data assimilation results. However this is expensive from a computational point of view since a function of depth involving 20 parameters has to be estimated instead of a single parameter. Moreover the obtained profile of C:Chl ratio is strongly site dependent and extrapolation of the model to other areas is therefore delicate. Some other studies (Doney et al., 1996; Lévy et al., 1998) propose to parameterize the C:Chl ratio as a static function of light in the water column. It is therefore varying in space and time. Here we propose a mechanical and more realistic representation of the dynamical variations of the C:Chl ratio with respect to environmental conditions. The main tool we use to achieve this objective is the BIOLOV model presented in the following section.

\subsection{The BIOLOV model}

Modelling growth of phytoplankton both limited by light and nitrogen has been an active research field in the previous years. It resulted in several models of various complexity. Some works describe with much details the involved mechanisms of coupling between carbon and nitrogen assimilation, resulting in complex models where many state variables are necessary to describe phytoplankton growth (Zonneveld, 1998; Flynn, 2001). These models are less convenient to integrate in a biogeochemical framework since they considerably increase the computational cost. Moreover the calibration of such models becomes a critic issue since the large number of parameters to be estimated may jeopardize the classical assimilation techniques. On the other hand there exists simpler models that focus on the main variables of interest: total cellular carbon, nitrogen and chlorophyll (Baumert, 1996; Geider et al., 1997). The application of these models have so far been limited to balanced growth

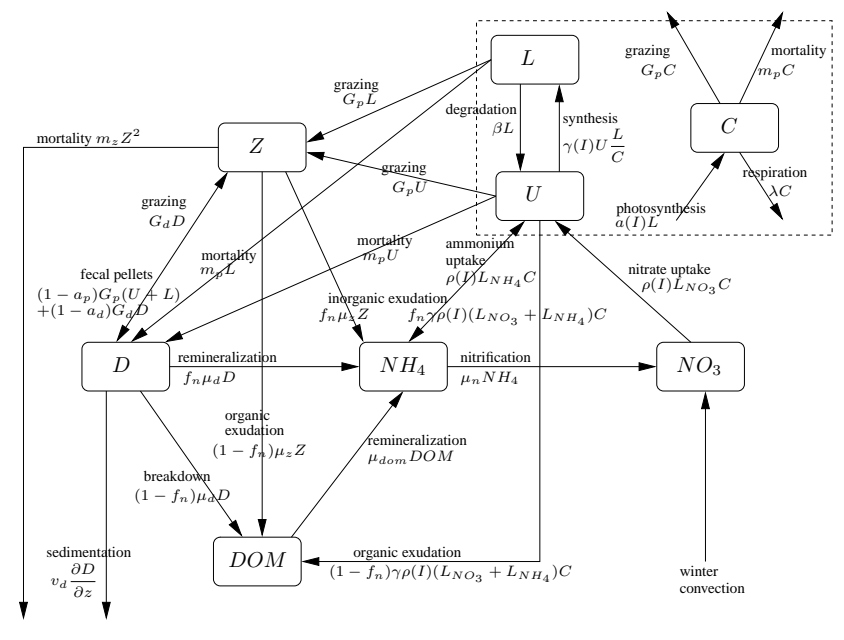

Fig. 6. Schematic representation of the compartments and processes of the new model.

conditions for which they have been validated. The BIOLOV model (Pawlowski et al., 2002) is a phytoplankton growth model which was developed and validated in chemostat experiments, under unbalanced growth conditions (see Fig. 1).

In the BIOLOV model phytoplankton is represented by 3 variables: the carbon $C$, the non-chlorophyllian nitrogen $U$ and the chlorophyllian nitrogen $L$. It was originally formulated for a chemostat as a system of ordinary differential equations describing the evolution of 4 state variables $C$ (expressed in mmolC. $\mathrm{m}^{-3}$ ), $U, L$ and $S$, the nitrogen source (expressed in mmolN.m $\left.{ }^{-3}\right)$. Let $f\left(\mathrm{mmolN} \cdot \mathrm{mmol} \mathrm{Chla}{ }^{-1}\right)$ denote the conversion factor from chlorophyllian nitrogen to chlorophyll $a$ (see Table 3): $\mathrm{Chl}=f L$. The model integrates both limitation by light and nitrogen and has been designed to have a simple formulation with few parameters and state variables representing measurable quantities in a photobioreactor or in the open ocean. Figure 5 shows a schematic representation of the model and its parameters are presented in Table 2.

Phytoplankton growth is assumed to be triggered by two distinct metabolic pathways: uptake and assimilation of nitrogen on one hand and carbon fixation through photosynthesis on the other hand.

The full nitrogen pathway consists in three steps. First nitrogen $(S)$ is uptaken by the cell into the cellular nitrogen pool $(U)$. The uptake rate is classically represented by a Monod kinetics,

$\rho_{m} \frac{S}{K_{S}+S}$.

In a second step, the nitrogen pool is used to produce chlorophyllian proteins $(L)$. The chlorophyll synthesis is assumed to be dependent on light intensity, $I$, and on the ratio $\frac{L}{C}$. It is also proportional to the nitrogen pool $U$. The rate of the reaction is therefore assumed to be given by $\gamma(I) U \frac{L}{C}$ where

$\gamma(I)=\frac{\alpha K_{L} I}{K_{I}+I} \frac{K_{C}}{K_{C}+I}$. 
Table 2. Parameters of the BIOLOV model.

\begin{tabular}{lccc}
\hline parameter & name & value & unit \\
\hline max. assimilation rate & $\rho_{m}$ & $5.787 \mathrm{E}-6$ & mmolN.mmolC $^{-1} . s^{-1}$ \\
half-saturation const. for assimilation & $K_{S}$ & 0.43 & $\mathrm{mmolN} \mathrm{m}^{-3}$ \\
max. Chl synthesis rate & $K_{L}$ & 6.59 & \\
Chl. synthesis threshold coefficient & $K_{C}$ & 33.0 & $\mu$ mol quanta.m $^{-2} . \mathrm{s}^{-1}$ \\
max. fixation rate for carbon & $\alpha$ & $2.7894 \mathrm{E}-4$ & $\mathrm{~s}^{-1}$ \\
half-saturation const. for carbon fixation & $K_{I}$ & 208.5 & $\mu$ mol quanta. $^{-2} . s^{-1}$ \\
respiration rate & $\lambda$ & $6.25 \mathrm{E}-7$ & $\mathrm{~s}^{-1}$ \\
Chl. degradation rate & $\beta$ & $3.9931 \mathrm{E}-6$ & $\mathrm{~s}^{-1}$ \\
\hline
\end{tabular}

Finally, a natural degradation of chlorophyll is also taken into account through a rate $\beta L$.

The carbon pathway results from two reactions. First, inorganic carbon (DIC Dissolved Inorganic Carbon) is incorporated into the cell through photosynthesis to form particulate carbon, $C$.

For sake of simplicity we assume a constant quantum yield, resulting thus in the photosynthesis rate per carbon unit $a(I) L / C$ with

$a(I)=\frac{\alpha I}{K_{I}+I}$.

This rate is highly dependent on light level and chlorophyll pigments which act as catalyzers for this reaction. This very simple expression compared to the one used e.g. by (Geider et al., 1997) allows to keep the model simple avoiding additional parameters that may limit the efficiency of the assimilation procedure.

Inorganic carbon is considered as non-limiting for phytoplankton growth in marine environment and therefore it does not intervene. Second, a proportion of the carbon is lost by respiration. The respiration rate is proportional to the carbon biomass and is written $\lambda C$.

\subsection{Combining the 1D NNPZD-DOM model and the BI-} OLOV model

Now that we have briefly described the 1D NNPZD-DOM model and the BIOLOV model we are able to construct our new model. Our goal is to embed the BIOLOV model into the NNPZD-DOM model, in order to obtain a model which can be compared to the DYFAMED data set and in which the carbon/chlorophyll ratio evolves dynamically. In line with our objective to compare the effect of different phytoplankton parametrization on prediction variability we kept unchanged the hydrodynamical model as well as the other compartments of the biological model.

Phytoplankton is not anymore represented by a single variable $P$ but by the 3 variables $U, L$ and $C$. Figure 6 shows a complete representation of the compartments and processes of the new model, and all parameters are presented in Table 3. The different reaction terms can now be written as follows.

$F_{\mathrm{NO}_{3}}=-\rho_{p}(I) L_{\mathrm{NO}_{3}} C+\mu_{n} \mathrm{NH}_{4}$,

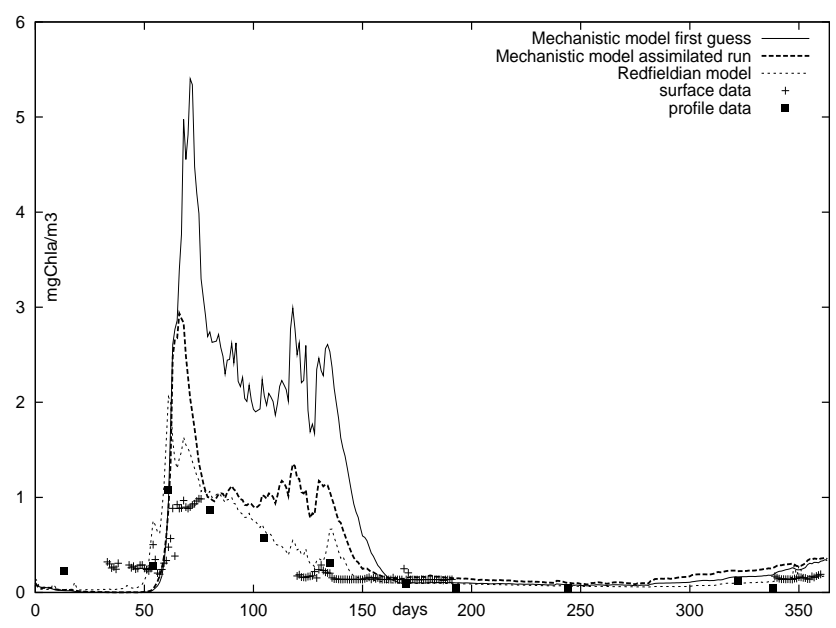

Fig. 7. Surface chlorophyll $\left(\mathrm{mgChla} / \mathrm{m}^{3}\right)$ computed with the Mechanistic model (first guess and assimilated run) and with the Redfieldian model. Crosses are the surface observations. Squares are the surface measurements taken from the chlorophyll profile set (Fig. 8).

$$
\begin{aligned}
F_{\mathrm{NH}_{4}}= & -\rho_{p}(I) L_{\mathrm{NH}_{4}} C+f_{n} \gamma \rho_{p}(I)\left(L_{\mathrm{NO}_{3}}+L_{\mathrm{NH}_{4}}\right) C \\
& +f_{n} \mu_{z} Z+f_{n} \mu_{d} D-\mu_{n} \mathrm{NH}_{4}+\mu_{d o m} D O M \\
F_{U}= & \rho_{p}(I) L_{\mathrm{NO}_{3}} C+\rho_{p}(I) L_{\mathrm{NH}_{4}} C-f_{n} \gamma \rho_{p}(I)\left(L_{\mathrm{NO}_{3}}+L_{\mathrm{NH}_{4}}\right) C \\
& -\left(1-f_{n}\right) \gamma \rho_{p}(I)\left(L_{\mathrm{NO}_{3}}+L_{\mathrm{NH}_{4}}\right) C-\gamma(I) U \frac{L}{C}+\beta L \\
& -G_{p}(U+L, D, Z) U-m_{p} U \\
F_{L}= & \gamma(I) U \frac{L}{C}-\beta L-m_{p} L-G_{p}(U+L, D, Z) L \\
F_{C}= & a(I) L-\lambda C-m_{p} C-G_{p}(U+L, D, Z) C \\
F_{Z}= & G_{p}(U+L, D, Z)(U+L)+G_{d}(U+L, D, Z) D \\
& -\left(1-a_{d}\right) G_{d}(U+L, D, Z) D \\
& -\left(1-a_{p}\right) G_{p}(U+L, D, Z)(U+L)-m_{z} Z^{2}-\mu_{z} Z \\
F_{D}= & \left(1-a_{p}\right) G_{p}(U+L, D, Z)(U+L) \\
& +\left(1-a_{d}\right) G_{d}(U+L, D, Z) D \\
& -G_{d}(U+L, D, Z) D+m_{p}(U+L) \\
& -f_{n} \mu_{d} D-\left(1-f_{n}\right) \mu_{d} D-v_{d} \frac{\partial D}{\partial z} \\
&
\end{aligned}
$$


Table 3. 33 parameters of the Mechanistic model.

\begin{tabular}{|c|c|c|c|}
\hline parameter & name & value & unit \\
\hline half-saturation const. for nutrients & $k_{n}$ & 0.3208 & $\operatorname{mmolN~m}{ }^{-3}$ \\
\hline phyto. exudation fraction & $\gamma$ & 0.0649 & \\
\hline zoo. nominal preference for phyto food & $r$ & 0.6279 & \\
\hline max. specific zoo. grazing rate & $g_{z}$ & $1.2152 \mathrm{E}-5$ & $s^{-1}$ \\
\hline half-saturation const. for grazing & $k_{z}$ & 1.291 & mmolN.m ${ }^{-3}$ \\
\hline non-assimilated phyto. by zoo. & $a_{p}$ & 0.333 & \\
\hline non-assimilated detritus by zoo. & $a_{d}$ & 0.555 & \\
\hline zoo. specific exudation rate & $\mu_{z}$ & $8.120 \mathrm{E}-7$ & $\mathrm{~s}^{-1}$ \\
\hline phyto. mortality rate & $m_{p}$ & $1.354 \mathrm{E}-6$ & $s^{-1}$ \\
\hline zoo. mortality rate & $m_{z}$ & $1.058 \mathrm{E}-7$ & $\operatorname{mmolN} \cdot \mathrm{m}^{-3} \cdot s^{-1}$ \\
\hline detritus breakdown rate & $\mu_{d}$ & $1.352 \mathrm{E}-6$ & $s^{-1}$ \\
\hline detritus sedimentation speed & $v_{d}$ & 4.1122E-5 & $\mathrm{m} \cdot \mathrm{s}^{-1}$ \\
\hline decay rate below the euphotic layer & $\tau$ & $5.5738 \mathrm{E}-5$ & $\mathrm{~s}^{-1}$ \\
\hline ratio of inorganic exudation & $f_{n}$ & 0.7488 & \\
\hline nitrification rate & $\mu_{n}$ & 3.0213E-7 & $\mathrm{s}^{-1}$ \\
\hline slow remineral. rate of $D O M$ to $\mathrm{NH}_{4}$ & $\mu_{d m}$ & $4.8675 \mathrm{E}-8$ & $\mathrm{~s}^{-1}$ \\
\hline coeff. for Martin's remineralization profile & $h_{r}$ & -0.858 & \\
\hline pigment absorption in red & $k_{r p}$ & 0.037 & $\mathrm{~m}^{-1} \cdot\left(\mathrm{mgChl} \cdot \mathrm{m}^{-3}\right)^{-l_{r}}$ \\
\hline pigment absorption in green & $k_{g p}$ & 0.074 & $\mathrm{~m}^{-1} \cdot\left(\mathrm{mgChl} \cdot \mathrm{m}^{-3}\right)^{-l_{g}}$ \\
\hline power law for absorption in red & $l_{r}$ & 0.629 & \\
\hline power law for absorption in green & $l_{g}$ & 0.674 & \\
\hline contribution of $\mathrm{Chl}$ to absorbing pigments & $r_{\text {pig }}$ & 0.7 & \\
\hline water absorptions in green & $k_{\mathrm{go}}$ & 0.0232 & $m^{-1}$ \\
\hline water absorptions in red & $k_{\mathrm{ro}}$ & 0.225 & $\mathrm{~m}^{-1}$ \\
\hline max. assimilation rate & $\rho_{m}$ & $8.6805 \mathrm{E}-6$ & mmolN.mmolC ${ }^{-1} \cdot s^{-1}$ \\
\hline light half-saturation const. for assimilation & $K_{I 2}$ & 104.25 & $\mu$ mol quanta.m ${ }^{-2} \cdot \mathrm{s}^{-1}$ \\
\hline Chl. synthesis threshold coefficient & $K_{C}$ & 33.0 & $\mu$ mol quanta.m $\mathrm{m}^{-2} \cdot \mathrm{s}^{-1}$ \\
\hline max. fixation rate for carbon & $\alpha$ & $2.7894 \mathrm{E}-4$ & $\mathrm{~s}^{-1}$ \\
\hline max. Chl. synthesis rate & $\alpha_{K}$ & $1.800 \mathrm{E}-3$ & $\mathrm{~s}^{-1}$ \\
\hline half-saturation const. for carbon fixation & $K_{I}$ & 208.5 & $\mu$ mol quanta.m ${ }^{-2} \cdot \mathrm{s}^{-1}$ \\
\hline respiration rate & $\lambda$ & $6.25 \mathrm{E}-7$ & $\mathrm{~s}^{-1}$ \\
\hline Chl. degradation rate & $\beta$ & 7.9862 E-7 & $\mathrm{s}^{-1}$ \\
\hline $\mathrm{L} / \mathrm{Chl}$ ratio & $f$ & 0.43 & mmolN.m ${ }^{-3} / \mathrm{mgChl} \cdot \mathrm{m}^{-3}$ \\
\hline
\end{tabular}

$$
\begin{aligned}
F_{D O M}= & \left(1-f_{n}\right) \gamma \rho_{p}(I)\left(L_{\mathrm{NO}_{3}}+L_{\mathrm{NH}_{4}}\right) C \\
& +\left(1-f_{n}\right) \mu_{z} Z+\left(1-f_{n}\right) \mu_{d} D-\mu_{d o m} D O M,
\end{aligned}
$$

where

$G_{p}=G_{p}(U+L, D, Z)$,

and

$G_{d}=G_{d}(U+L, D, Z)$.

Let us make a few comments on some important modelled processes:

\section{- nutrient uptake:}

Contrary to the BIOLOV model not only nitrate but also ammonium is represented in the model. However the uptake rate still uses a Monod kinetics as in the BIOLOV model (hence $S=\mathrm{NO}_{3}+\mathrm{NH}_{4}$ ),

$$
L_{\mathrm{NO}_{3}}+L_{\mathrm{NH}_{4}}=\frac{\mathrm{NO}_{3}+\mathrm{NH}_{4}}{k_{n}+\mathrm{NO}_{3}+\mathrm{NH}_{4}} .
$$

Concerning the BIOLOV model the new variable $C$ appears in the formulation of the uptake rate,

$\rho_{p}(I)\left(L_{\mathrm{NO}_{3}}+L_{\mathrm{NH}_{4}}\right) C$.

However in the simplest version of the BIOLOV model the maximum uptake rate is a constant, $\rho_{m}$, and the uptake rate does not depend explicitly on light. Numerical sensitivity studies reinforced by light dark chemostat experiments suggested that this is a too raw approximation in our 1D DYFAMED context. We therefore choose to allow light dependence of the maximum uptake rate through the following formulation:

$\rho_{p}(I)=\frac{\rho_{m} I}{K_{I 2}+I}$.

- Concerning the NNPZDDOM model phytoplankton organic and inorganic exudation are proportional to the total uptake of nitrate and ammonium (Eq. 19). 

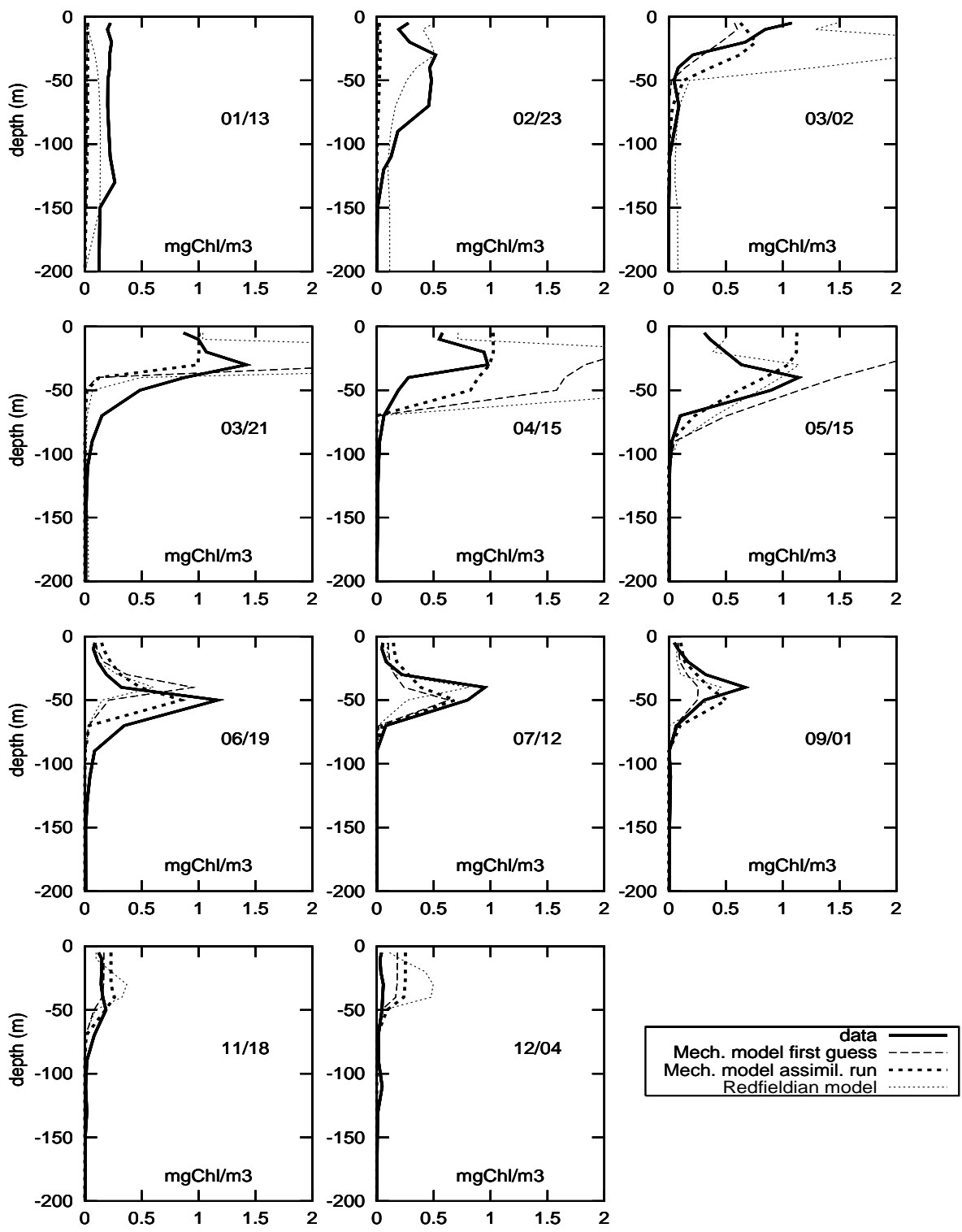

Fig. 8. Chlorophyll profiles (mgChla $/ \mathrm{m}^{3}$ ) computed with the Mechanistic model (first guess and assimilated run) and with the Redfieldian model. Depth in meters.

\section{- Phytoplankton mortality and zooplankton grazing:}

Phytoplankton mortality appears in the 3 equations for $U, L$ and $C$. The mortality rate, $m_{p}$, is the same for each of these variables.

In the same way, zooplankton grazing on phytoplankton now appears in each of the 3 equations for $U, L$ and $C$. The grazing rate $G_{p}(U+L, D, Z)$ is the same for each of these variables $(U+L$ represents total phytoplanktonic nitrogen).

The carbon/chlorophyll ratio in $\mathrm{mgC} . \mathrm{mgChla}^{-1}$ (computed as $12 f \frac{C}{L}$ ) is now a diagnostic variable of the model and evolves dynamically in space and time. Chlorophyll data can be directly compared to the variable $f L$ of the model, whereas in former studies phytoplankton and chlorophyll were related through a linear relation, $\frac{12 P r_{d}}{r_{c}}$ (where $r_{d}$ is the $\mathrm{C}: \mathrm{N}$ ratio and $r_{c}$ the $\mathrm{C}: \mathrm{Chl}$ ratio), in which the poorly known $\mathrm{C}$ : Chl ratio played a crucial role.

\section{Calibration of the new model using data assimilation}

\subsection{The DYFAMED data set}

The model general set up is the same as in Mémery et al. (2002) and Faugeras et al. (2003). The standard run consists of the simulation of year 1997. The simulation is forced with ECMWF atmospheric data, which give the wind stresses and heat fluxes every $6 \mathrm{~h}$.

The data used in this study are monthly chlorophyll and nitrate profiles collected during year 1997 at the DYFAMED station, and surface fluorescence data measured by the Carioca buoy (Hood and Merlivat, 2001) moored at DYFAMED 

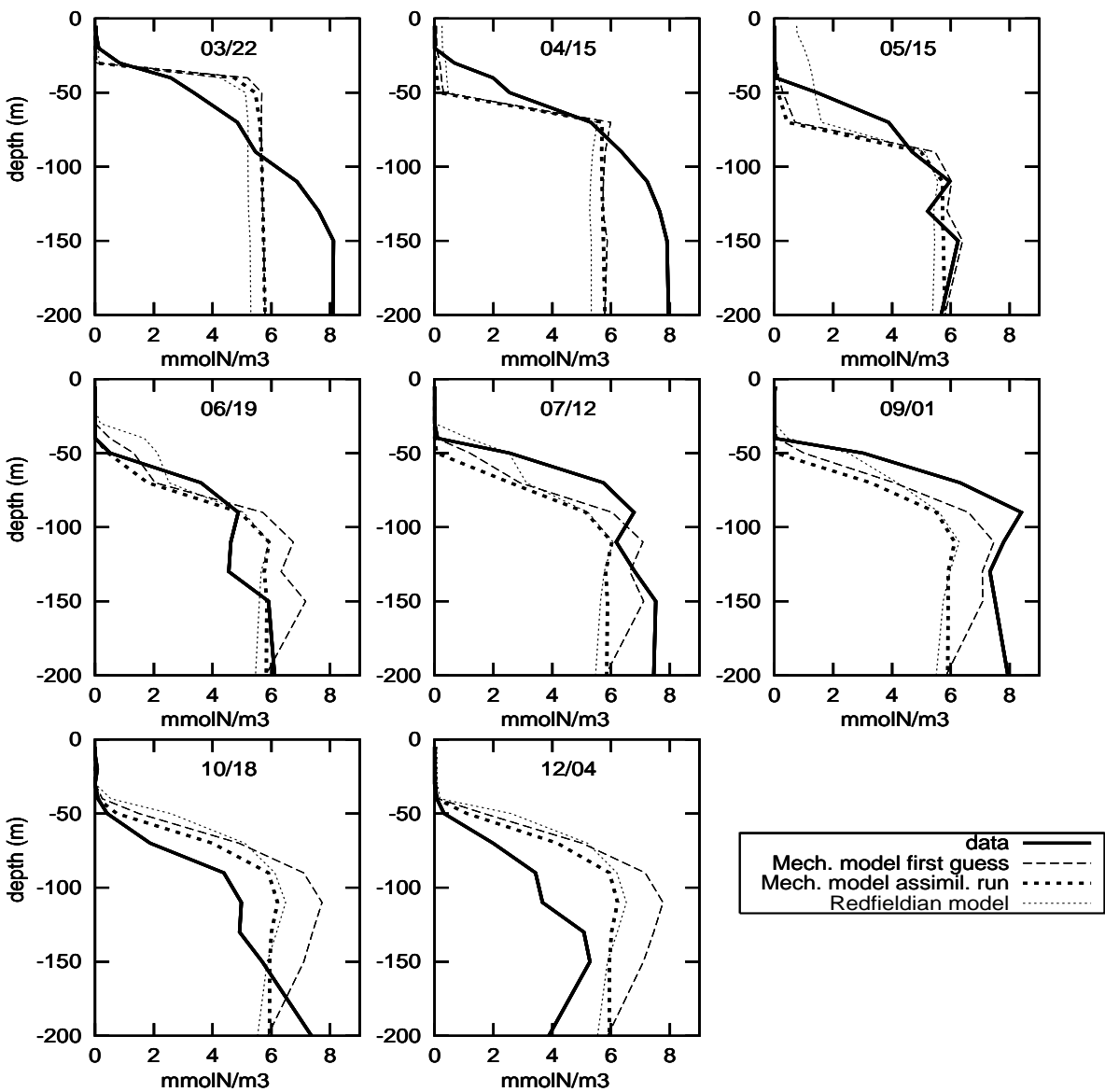

Fig. 9. $\mathrm{NO}_{3}$ profiles $\left(\mathrm{mmolN} / \mathrm{m}^{3}\right.$ ) computed with the Mechanistic model (first guess and assimilated run) and with the Redfieldian model. Depth in meters.

in 1997 (Figs. 7, 8, 9). Following the conclusions of Faugeras et al. (2003) concerning the necessity to use flux and zooplankton data in the parameter estimation process, we also make use of annual estimates of total production (TP), nitrate uptake (NU) and export fluxes (EF, estimated from disparate measurements undertaken in the 90s), and of the zooplankton content estimated during a special cruise in May 1995 (Andersen and Prieur, 2000).

\subsection{Parameter estimation}

The purpose of parameter estimation is to find a set of optimal parameters that minimises a cost function, $J$, which measures the distance, in a weighted least-squares sense, between the model's solution and the observations. The optimisation is carried out using the quasi-Newton algorithm implemented in the $n 1 q n 3$ Fortran subroutine of Gilbert and Lemaréchal (1989). The computation of the gradient of $J$ with respect to control parameters is required at each step of the minimisation. This gradient results in one integration of the adjoint model. The adjoint code was partially obtained using the automatic differentiation program Odyssée (Faure and Papegay, 1997; Griewank, 2000), which is an efficient tool for obtaining adjoint codes since it enables the automatic production of adjoint instructions. This so called variational adjoint method has already been applied in marine biogeochemistry by several authors (see Lawson et al., 1995, for example).

As shown in Table 3, the biological parameters have very different orders of magnitude. To avoid any numerical difficulties which might arise from this during the minimization, we adimensionalise the parameter vector $K$, dividing each parameter $K_{i}$ by its first guess value $K_{i}^{0}, k_{i}=K_{i} / K_{i}^{0}$. Such a non-dimensionalisation procedure can be regarded as a preconditioning for minimization. The control variable is $k$ of size $p$, where $p$ is the number of parameters, and $k$ is dimensionless.

The model-data misfit part, $J_{0}$, of the cost function can be written as the sum of five terms:

$$
J_{0}(k)=J_{s c}(k)+J_{c p}(k)+J_{n p}(k)+J_{\text {zoo }}(k)+J_{\text {flux }}(k) .
$$

Let $d$ denote the data and $\phi$ the operator which, to a set of parameter $k$, associates the equivalents to the data computed by the model, $\phi(k)$. Then $J_{s c}$, the cost related to the $n s c$ surface chlorophyll observations, $d s c$ reads:

$J_{s c}(k)=\frac{1}{2} \sum_{i=1}^{n c s} w_{s c}\left(\phi_{s c}(k)_{i}-d s c_{i}\right)^{2}$ 

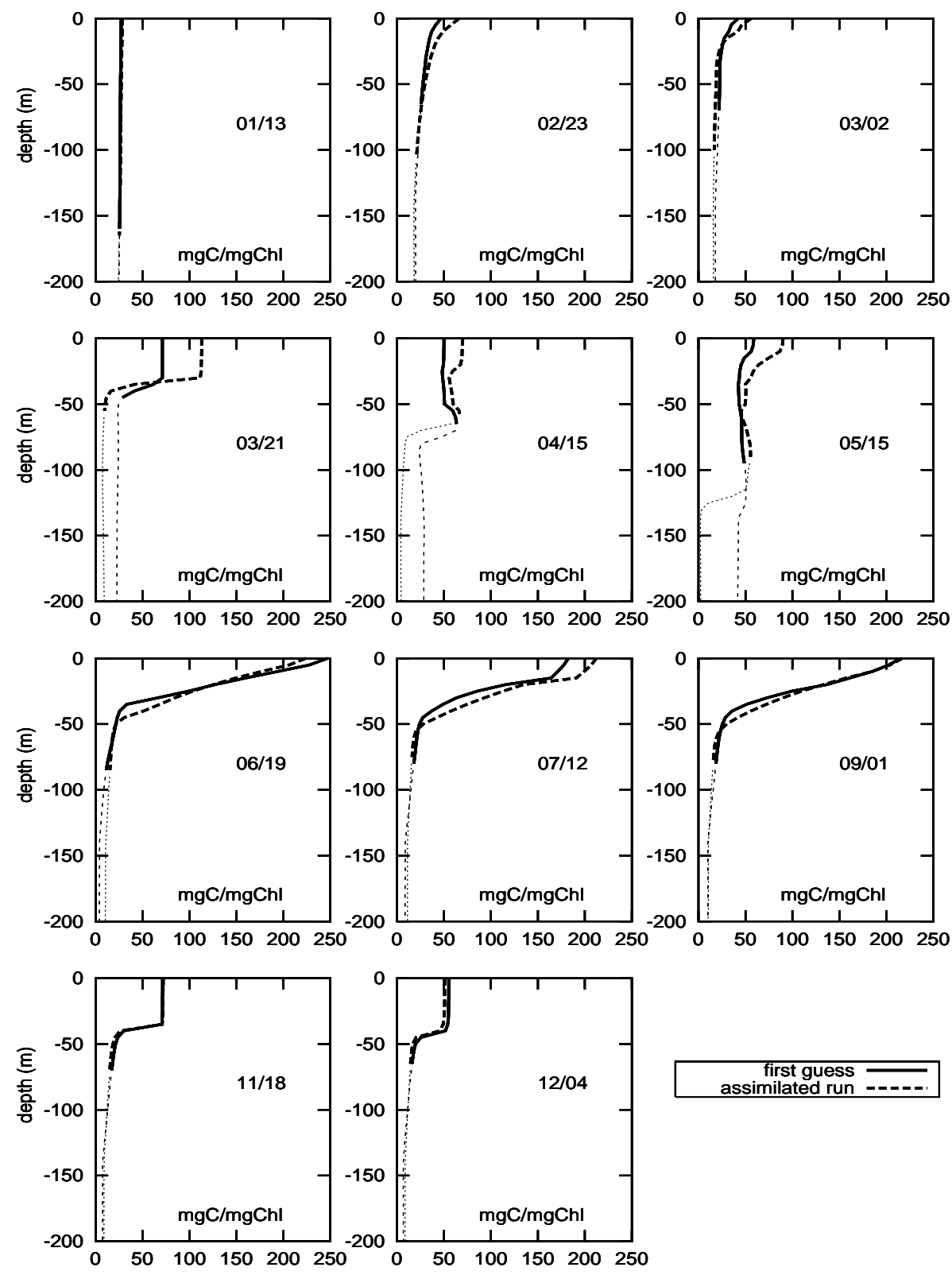

Fig. 10. Mean carbon to chlorophyll ratio profiles for year 1997 at DYFAMED. Thin dashed lines indicate that the algal biomass is very weak, and thus that the ratio is computed with very small values of $\mathrm{C}$ or $\mathrm{Chl}$.

$J_{c p}$ is related to the $n c p$ chlorophyll profile observations, $d c p$ ( $m$ cp measurement points on the vertical),

$J_{c p}(k)=\frac{1}{2} \sum_{i=1}^{n c p} \sum_{l=1}^{m c p} w_{c p}\left(\phi_{c p}(k)_{i, l}-d c p_{i, l}\right)^{2}$.

$J_{n p}$ is related to the $n n p \mathrm{NO}_{3}$ profile observations, $\operatorname{dnp}$ ( $m n p$ measurement points on the vertical),

$J_{n p}(k)=\frac{1}{2} \sum_{i=1}^{n n p} \sum_{l=1}^{m n p} w_{n p}\left(\phi_{n p}(k)_{i, l}-d n p_{i, l}\right)^{2}$.

$J_{\mathrm{zoo}}$ is related to the single zooplankton data,

$J_{\mathrm{zoo}}(k)=\frac{w_{\mathrm{zoo}}}{2}\left(\phi_{\mathrm{zoo}}(k)-d \mathrm{zoo}\right)^{2}$.
$J_{\text {flux }}$ is related to the TP, NU and EF data estimates.

$$
\begin{aligned}
J_{\text {flux }}(k)= & \frac{w_{t p}}{2}\left(\phi_{t p}(k)-d t p\right)^{2}+\frac{w_{n u}}{2}\left(\phi_{n u}(k)-d n u\right)^{2}+ \\
& \frac{w_{e f}}{2}\left(\phi_{e f}(k)-d e f\right)^{2} .
\end{aligned}
$$

The different weights $w$ are composed of the square of the assumed a priori observation errors and of a scaling factor accounting for the number of each type of observation. Therefore, we have $w_{c s}=\frac{1}{n c s . \sigma_{c s}^{2}}, w_{c p}=\frac{1}{(n c p . m c p) \sigma_{c p}^{2}}$, and $w_{n p}=\frac{1}{(n n p \cdot m n p) \sigma_{n p}^{2}}$. 

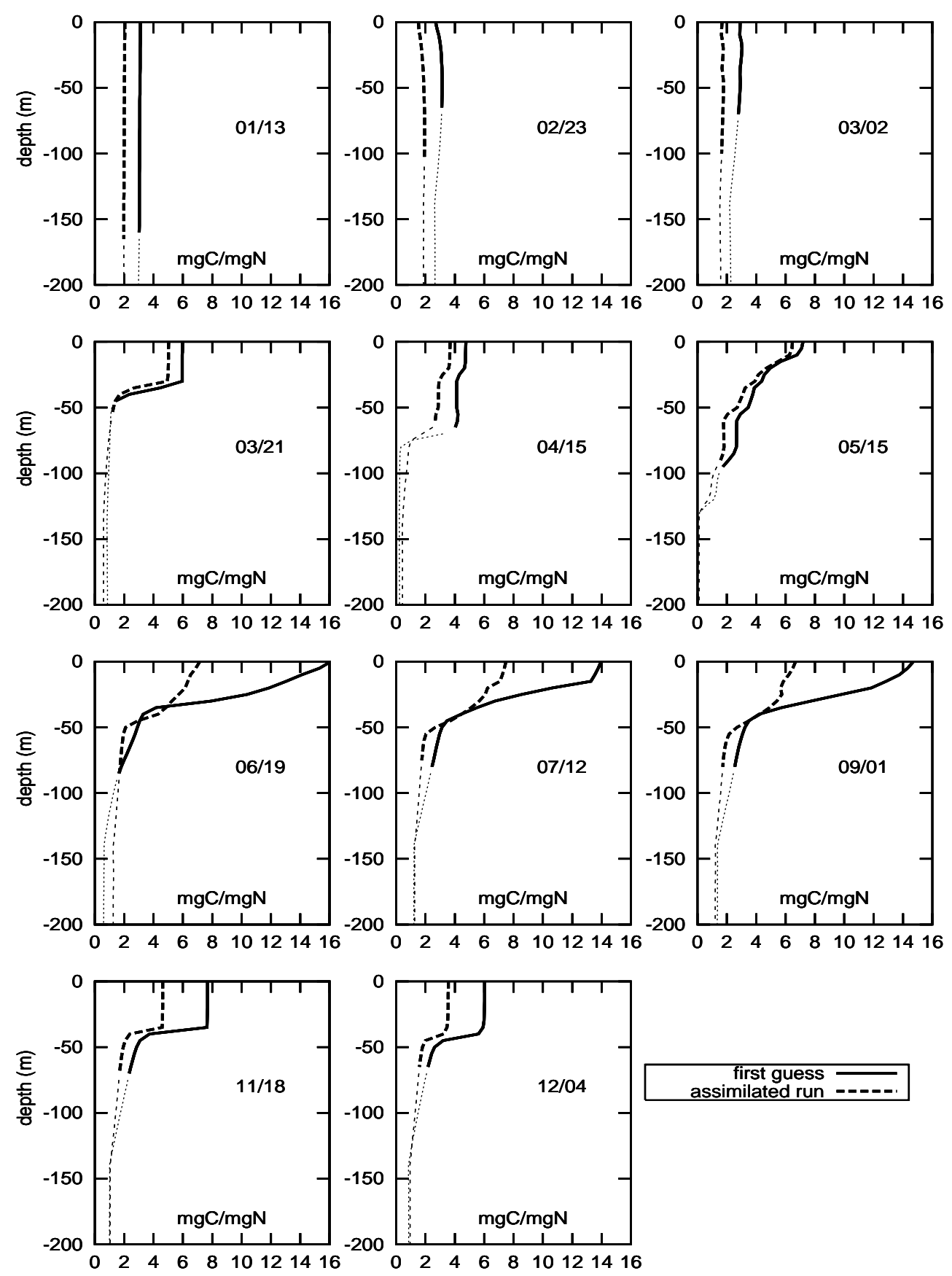

Fig. 11. Mean carbon to nitrogen ratio profiles for year 1997 at DYFAMED. Thin dashed lines indicate that the algal biomass is very weak, and thus that the ratio is computed with very small values of $\mathrm{C}, \mathrm{Chl}$ or $\mathrm{N}$.

We also add two penalty terms to $J_{0}$. The first term,

$J_{p}(k)=\frac{1}{2} \sum_{i=1}^{p} w_{i}\left(k_{i}-k_{i}^{0}\right)^{2}$,

accounts for the a priori parameter values and their standard deviations, $\sigma_{i}=\frac{1}{\sqrt{w_{i}}}$. This term forces the minimization to avoid biologically absurd optimal parameter values.

The second term,

$$
J_{r c}(k)=\frac{w_{r c}}{2} \sum_{j} \sum_{n}\left(\left(12 f(C / L)_{j, n}-250\right)^{+}\right)^{2},
$$

where $n$ refers to time and $j$ to space, is added to penalize carbon/chlorophyll ratio values greater than 250 $\mathrm{mgC} . \mathrm{mg} \mathrm{Chla}{ }^{-1}$ which is considered as an upper bound by biologists. The choice of the weight $w_{r c}$ is not straightforward, since a compromise has to be found between the quality of the minimization of $J_{0}$ and realistic bound for the carbon/chlorophyll ratios. In practice, $w_{r c}$ was chosen so that the data misfit part of the cost and its regularization part are balanced. 


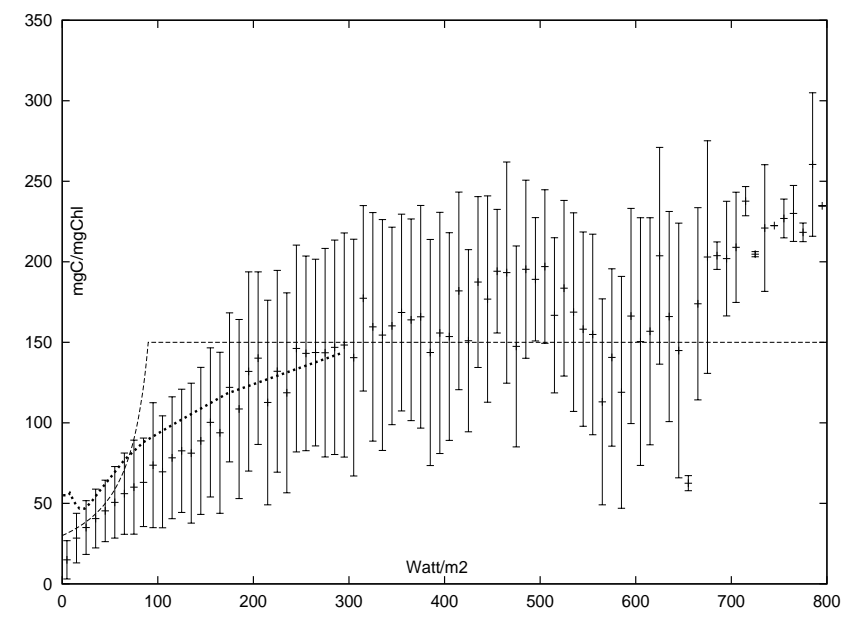

Fig. 12. Carbon to chlorophyll ratio versus light intensity. Mean values and standard deviation by interval of light intensity of length $10 \mathrm{Watt} / \mathrm{m}^{2}$ calculated for the whole water column during year 1997. The thin dashed line corresponds to the parameterization of this ratio as function of light given by Eqs. (27) and (28). The bold dashed line corresponds to the ratio obtained in Faugeras et al. (2003) plotted against the mean light intensity in the water column.

Table 4. Flux data (from Marty and Chiaverini, 2002) and computed fluxes at 200m with the Redfieldian NNPZD-DOM model and the Mechanistic model. Values are given in $\mathrm{gC} \cdot \mathrm{m}^{-2} \cdot \mathrm{y}^{-1}$. NU stands for $\mathrm{NO}_{3}$ uptake, TP for total production, $\mathrm{EF}$ for export flux.

\begin{tabular}{lllll}
\hline flux & data & $\begin{array}{l}\text { Redfieldian } \\
\text { model }\end{array}$ & $\begin{array}{l}\text { Mech. } \\
\text { model } \\
\text { first guess }\end{array}$ & $\begin{array}{l}\text { Mech. } \\
\text { model } \\
\text { opt. }\end{array}$ \\
\hline NU & $42 \pm 15$ & 49.6 & 48.7 & 47.2 \\
TP & $156 \pm 30$ & 136.2 & 92.8 & 106.3 \\
EF & $2 \pm 0.8$ & 2.4 & 0.2 & 2.5 \\
\hline
\end{tabular}

\section{Numerical results}

\subsection{Model fit to the DYFAMED data}

An a priori parameter set is constructed in the following way: parameters which were already included in the NNPZDDOM model are given the values estimated using data from the DYFAMED station in Faugeras et al. (2003). Parameters coming from the BIOLOV model are given the values proposed in Pawlowski et al. (2002). A few parameters were then hand-tuned empirically in order to obtain a qualitatively correct first guess simulation. Note that since parameter $K_{L}$ (Table 2) only enters the equations of the BIOLOV model in the $\alpha K_{L}$ product form (Eq. 15), for the sake of parameter estimation those two parameters are concatenated in a single parameter $\alpha_{K}$.

A first run is carried out using the a priori parameter set and without any data assimilation. Figures 7, 8 and 9 show surface chlorophyll, chlorophyll and nitrate profiles computed with the Mechanistic model versus the data (for the

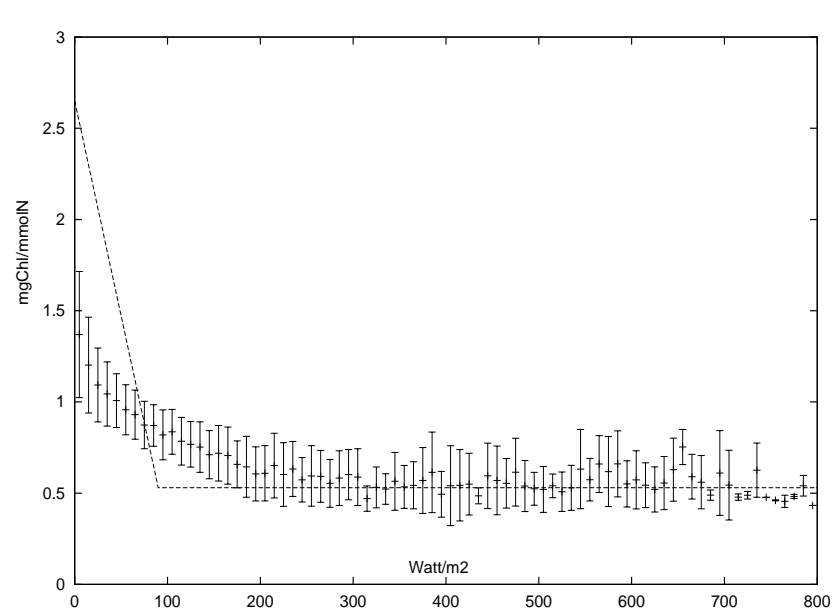

Fig. 13. Chlorophyll to nitrogen ratio versus light intensity. Mean values and standard deviation by interval of light intensity of length $10 \mathrm{Watt} / \mathrm{m}^{2}$ computed for the whole water column during year 1997. The dashed line corresponds to the parameterization of this ratio as function of light given by Eqs. (27) and (28).

sake of completeness the results given by the Redfieldian model with the light dependent C:Chl ratio described in Section 4.2 are also depicted on the same figures). The seasonal variability is well reproduced, but the spring bloom appears to be too strong and the transition towards oligotrophy poorly represented. This first guess run predicts reasonably good TP and NU fluxes estimates (Table 4). On the other hand, the export flux is underestimated and is associated with an underestimation of the zooplankton content (Table 5).

The evolution over time of the chlorophyll and nitrate data profiles (Figs. 8, 9) reflects the seasonal variability at DYFAMED. Winter mixing brings nutrients to the surface, but the short residence time of algae in the euphotic layer, swept along by strong vertical motions, prevents the development of biomass. As the year progresses, the surface layer becomes more stable, thus allowing the winter nutrient enrichment to be utilized continuously and finally allowing the algae bloom. From mid-May to November, the situation remains fairly stable with the upper layer nutrient content very low, and the system mainly oligotrophic and characterized by a deep chlorophyll maximum. It may be noticed that the nitrate profiles show strong variability below $100 \mathrm{~m}$. This variability cannot be attributed to biological processes since these occur closer to the surface, and it is therefore most likely due to horizontal advection. It cannot therefore be captured by the model. During the oligotrophic period, the location of the nitracline and the deep chlorophyll maximum is fairly constant. This may be an indication of the absence of strong Ekman pumping and a crude justification for neglecting vertical advection.

In order to calibrate the simulation we estimated $25 \mathrm{pa}$ rameters among the 33 parameters of the model. Following the sensitivity analysis conducted in Faugeras et al. (2003) which proved that the optical model parameters as well as parameter $h_{r}$ can not be recovered from the DYFAMED data 
Table 5. Zooplankton content data and computed values at $200 \mathrm{~m}$, with the Redfieldian NNPZD-DOM model and the Mechanistic model, for May 1997, in mmolN $\mathrm{m}^{-2}$.

\begin{tabular}{llll}
\hline data & $\begin{array}{l}\text { Redfieldian } \\
\text { model }\end{array}$ & $\begin{array}{l}\text { Mech. } \\
\text { model first } \\
\text { guess }\end{array}$ & $\begin{array}{l}\text { Mech. } \\
\text { model } \\
\text { opt. }\end{array}$ \\
\hline $20 \pm 10$ & 33.3 & 1.3 & 19.1 \\
\hline
\end{tabular}

Table 6. Optimal adimensionalized $\left(K / K^{0}\right)$ parameters of the Mechanistic model.

\begin{tabular}{cl}
\hline parameter & $\begin{array}{l}\text { optimal set } \\
k^{\mathrm{opt}}\end{array}$ \\
\hline$k_{n}$ & 0.944 \\
$\gamma$ & 0.971 \\
$r$ & 0.404 \\
$g_{z}$ & 1.314 \\
$k_{z}$ & 1.135 \\
$a_{p}$ & 0.855 \\
$a_{d}$ & 0.802 \\
$\mu_{z}$ & 1.220 \\
$m_{p}$ & 1.394 \\
$m_{z}$ & 0.850 \\
$\mu_{d}$ & 0.867 \\
$v_{d}$ & 0.347 \\
$\tau$ & 1.003 \\
$f_{n}$ & 0.947 \\
$\mu_{n}$ & 0.993 \\
$\mu_{d m}$ & 1.299 \\
$\rho_{m}$ & 1.335 \\
$K_{I 2}$ & 0.590 \\
$K_{C}$ & 0.740 \\
$\alpha$ & 1.218 \\
$\alpha_{K}$ & 0.464 \\
$K_{I}$ & 1.041 \\
$\lambda$ & 1.121 \\
$\beta$ & 1.059 \\
$\mathrm{f}$ & 0.948 \\
\hline &
\end{tabular}

set, we did not include them in the control vector. The optimal parameter set is shown on Table 6 .

The parameter estimation procedure resulted in several improvements in the simulation. Bloom intensity is divided by a factor of two, in agreement with the observations (Fig. 7). Chlorophyll profiles during the bloom (dates 2 and 21 March on Fig. 8) also show a better fit with the data. The subsurface chlorophyll maximum is well simulated in oligotrophic regime (dates 19 June, 12 July and 1 September). This results from the use of a variable $\mathrm{C}: \mathrm{Chl}$ ratio. Concerning $\mathrm{NO}_{3}$ profiles the improvement is less significant. This problem already occurred in former studies and was attributed to the fact that these profiles are affected by 3D physics not taken into account in the model. Data assimilation also forces the
Table 7. Total production computed at $200 \mathrm{~m}$ with the Redfieldian model and the Mechanistic model. "TP in C" is the flux computed in carbon unit $\left(\mathrm{gC} \cdot \mathrm{m}^{-2} \cdot \mathrm{y}^{-1}\right)$ and "TP in $\mathrm{N}$ " is the flux computed in nitrogen unit $\left(\mathrm{gN} \cdot \mathrm{m}^{-2} \cdot \mathrm{y}^{-1}\right)$.

\begin{tabular}{ccc}
\hline flux & Redfieldian model & Mechanistic model \\
\hline TP in C & 136.2 & 106.3 \\
TP in N & 23.9 & 28.5 \\
\hline
\end{tabular}

model to predict correct zooplankton quantities (Table 5) and correct fluxes estimates (Table 4). Concerning the total production flux (TP), it is worth to notice that if in the Redfieldian model it is computed in nitrogen unit and then converted to carbon unit using a constant $\mathrm{C}: \mathrm{N}$ ratio, in the Mechanistic model this flux is directly computed in carbon unit through the formulation

$T P=a(I) L-\lambda C\left(\mathrm{mmolC} / \mathrm{m}^{3} / \mathrm{s}\right)$.

This formulation can also lead to negative production values when respiration is stronger than photosynthesis. This situation occurs at least every night in the model when $a(I)=0$. Table 7 shows total production for both the mechanistic and the Redfieldian model computed in carbon unit or nitrogen unit. Total production in carbon unit is higher for the Redfieldian model than for the Mechanistic model whereas the contrary holds for this flux computed in nitrogen unit. However this difference cannot be considered as significant with regard to the uncertainty of the data. The same remark holds for the differences which appear in Figs. 7, 8 and 9 between the Mechanistic model and the Redfieldian model.

Figure 10 shows the $\mathrm{C}: \mathrm{Chl}$ ratio profiles at the same dates than the Chl profiles of Fig. 8. The Mechanistic model simulates values which are in accordance with what one should have expected. Globally the ratio decreases with depth that is to say with light. This is certainly a consequence of the BIOLOV model's structure which was designed to simulate these features observed experimentally at steady state (Pawlowski et al. (2002), Geider et al. (1998), Chalup and Laws (1990)). The bloom and post-bloom period correspond to relatively low $\mathrm{C}$ : Chl ratio values (lower than 100 $\mathrm{mgC} / \mathrm{mgChl}$ ) and relatively homogeneous profiles. On the contrary during summer when the oligotrophic regime occurs surface values are high (between 200 and $250 \mathrm{mgC} / \mathrm{mgChl}$ ) and the ratio rapidly decreases with depth from 0 to about $50 \mathrm{~m}$ which corresponds to the depth of the subsurface chlorophyll maximum.

With the Mechanistic model the $\mathrm{C}: \mathrm{N}$ ratio, computed as $C /(U+L)$, evolves dynamically. Figure 11 shows the C:N ratio profiles at the same dates than the Chl profiles of Fig. 8 . As for the C:Chl ratio, it strongly varies with depth and time which is not at all the usual hypothesis made in such a biogeochemical model where this ratio is taken equal to 6.625 $\mathrm{mmolC} / \mathrm{mmolN}$. This variability is consistent with experimental observations (Droop, 1968; Sciandra et al., 2000), 

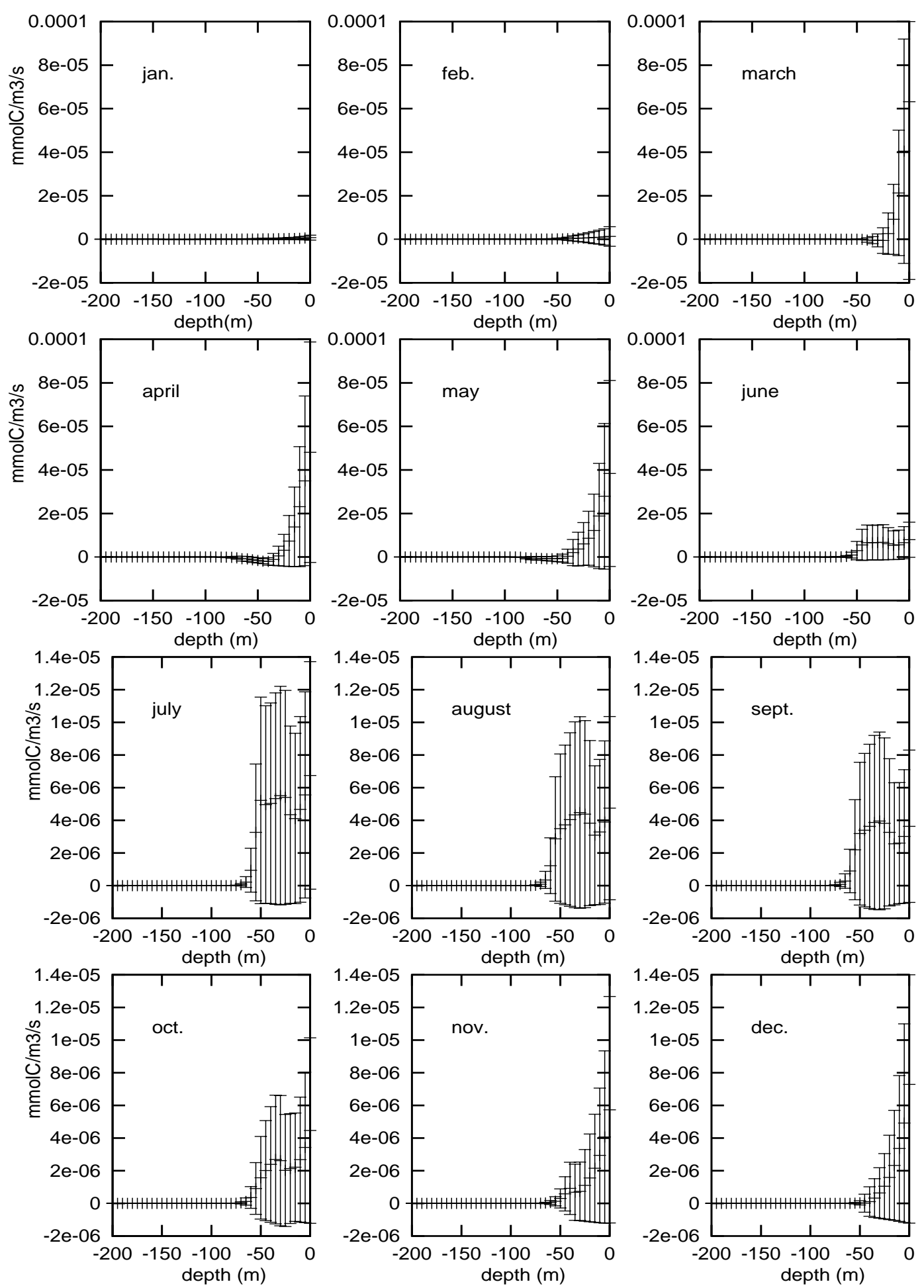

Fig. 14. Monthly total production profiles for the Mechanistic model.

even if the values reach sometimes too low thresholds probably due to the higher carbon losses by respiration than nitrogen losses in strong light limitation conditions. Table 8 gives the mean $\mathrm{C}: \mathrm{Chl}$ and $\mathrm{C}: \mathrm{N}$ ratios computed with the Mechanistic model. The low values reached by the $\mathrm{C}: \mathrm{N}$ ratio lead to a mean value of this ratio lower than the classical Redfield ratio.

\subsection{Variability of the predicted ratios}

In order to better assess the results of the Mechanistic model, and to first discuss the variability of the $\mathrm{C}$ : Chl ratio we compare the obtained values with those computed as a function of light, as proposed in (Doney et al. (1996), Lévy et al. (1998)). With obvious notations this parameterization is written as 

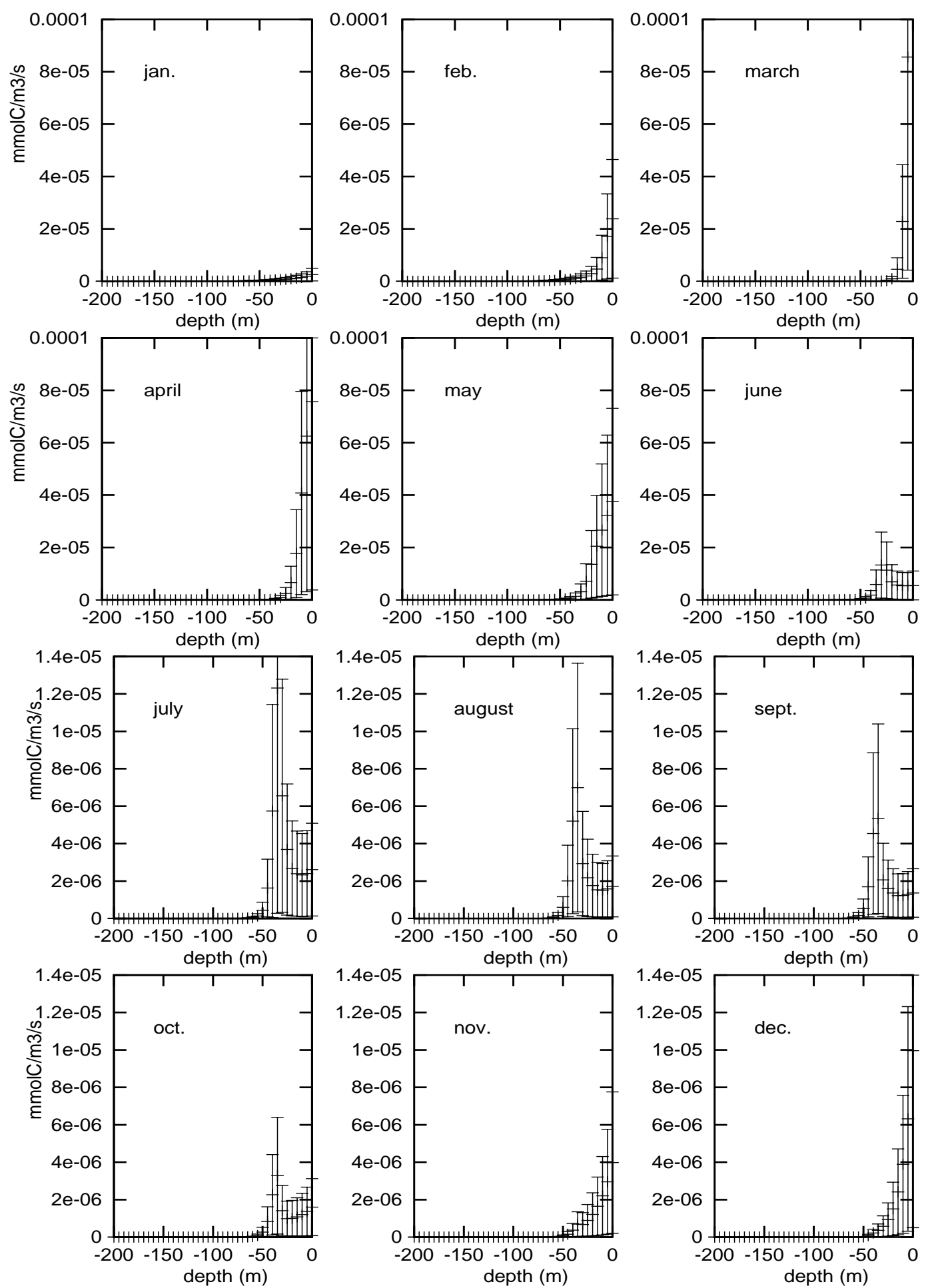

Fig. 15. Monthly total production profiles for the Redfieldian NNPZD-DOM model.

follows:

$R_{\mathrm{C}: \mathrm{Chl}}(I)=12 \cdot R_{\mathrm{C}: \mathrm{N}} / R_{\mathrm{Chl}: \mathrm{N}}(I)$,

where $R_{\mathrm{C}: \mathrm{N}}$ (in $\mathrm{molC} / \mathrm{molN}$ ) is fixed and

$$
\begin{aligned}
R_{\mathrm{Chl}: \mathrm{N}}(I) & =\left[R_{\mathrm{Chl}: \mathrm{N}}^{\min }-\left(R_{\mathrm{Chl}: \mathrm{N}}^{\max }-R_{\mathrm{Chl:N}}^{\min }\right) I / I_{\mathrm{max}}\right] \\
& =R_{\mathrm{Chl}: \mathrm{N}}^{\min } I<I_{\max }, \\
& \text { if } I \geq I_{\max },
\end{aligned}
$$

where $R_{\mathrm{Chl}: \mathrm{N}}^{\min }, R_{\mathrm{Chl:N}}^{\max }$ and $I_{\max }$ are fixed parameters.
Figure 12 shows the $\mathrm{C}$ :Chl ratio computed with the Mechanistic model. The light intensity was discretized in intervals of $10 \mathrm{~W} / \mathrm{m}^{2}$. In each interval the value of the considered ratio was computed as well as its standard deviation. Two other C:Chl ratios are also plotted on the same figure: the one that would have been obtained with parameterization (Eq. 27), and the one obtained in Faugeras et al. (2003). This 
Table 8. Mean C:Chl (mgC/mgChl) and C:N (mgN/mgN) ratios and standard deviations computed with the Mechanistic model. The average is taken over the whole year and over the 50 first meters of the water column.

\begin{tabular}{cc}
\hline C:Chl & C:N \\
\hline $82.0 \pm 39.1$ & $4.2 \pm 1.5$ \\
\hline
\end{tabular}

latter which was originally computed as function of depth was transposed to a function of light on the basis of mean light intensity in the water column. This is the reason why no value is given for large values of light intensity which do not occur often in the simulation. The first remark is that the general form of the curve obtained with Eq. (27) fits the data cloud issued from the Mechanistic model. It is very probable that adjusting the parameters provided in Doney et al. (1996) and Lévy et al. (1998) we would be able to have a good adjustment. The second remark is that the curve obtained in Faugeras et al. (2003) fits the data cloud even better. However, the main outcome of this comparison is the huge variability of this ratio as predicted by our model. The variation can easily reach $100 \%$ of the predictions meaning thus that the coupling between carbon and chlorophyll can be very loose. Figure 13 shows the Chl:N ratio. Again variability arises from the model compared to the values given by parameterization (Eq. 27).

\subsection{Variability of the predicted fluxes}

The variability of total production has been estimated each month for both models as presented on Figs. 14 and 15. First it appears that this variability is much higher close to the surface, with a maximum for the nitracline in summer. The fluxes vary generally much more for our model than for the previous model, especially at the surface. It is worth noting that the total production in carbon units is approximately the same for both model since this data has been used during the assimilation step to constrain the data (Table 4).

This higher variability probably reflects the ability of the phytoplankton compartment in the BIOLOV model to promptly react to optimal conditions for carbon incorporation. This faculty results from the partial uncoupling between nitrogen and carbon incorporation as described by the BIOLOV model.

With Fig. 16, showing the time evolution during year 1997 of total production for both the Redfieldian and the Mechanistic model, and with Fig. 17 showing the time evolution of the C:N ratio, important points rise. First the seasonal variability of the $\mathrm{C}: \mathrm{N}$ ratio follows the one measured in the northeast Atlantic Ocean by Körtzinger et al. (2001): an increase from low early bloom values to high post-bloom/oligotrophic values. Second this seasonal variability enables the Mechanistic model to simulate higher summer production in carbon unit than the Redfieldian model (and thus lower in winter in

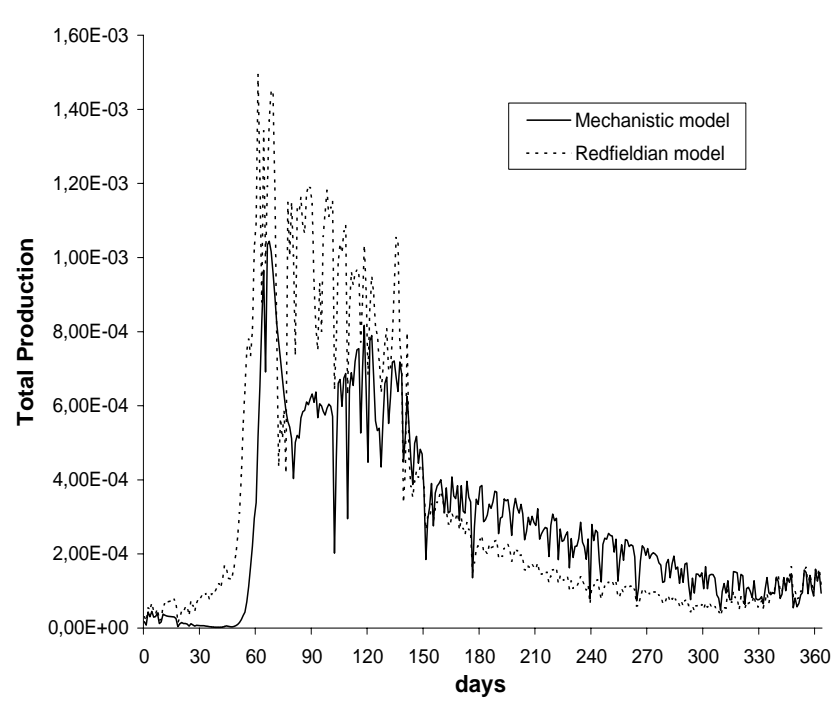

Fig. 16. Total production (mmolC.m $\left.\mathrm{m}^{-2} \cdot \mathrm{s}^{-1}\right)$ integrated on $100 \mathrm{~m}$, computed with the Mechanistic model and with the Redfieldian model.

order to give an annual value similar to the one given by the Redfieldian model). This clearly is a central point in our results since it has already been noticed that Redfieldian models predicted too low production values in summer (Mémery et al., 2002) and since the accurate prediction of production is important in the study of the carbon cycle.

\section{Conclusion: benefits of a more mechanistic model}

It was shown in Faugeras et al. (2003) that the data assimilation results could not be satisfying if the $\mathrm{C}$ :Chl ratio was kept constant for the Monod type phytoplankton models. The introduction of an empirical $\mathrm{C}: \mathrm{Chl}$ ratio parameterized by depth led to good results, especially when the fluxes data were assimilated. However this empirical approach may reveal difficult to extrapolate to other areas.

In our approach the idea consisted in providing a mechanical parameterization to this ratio by taking into account the nonlinear coupling between limitation by light and by nitrogen. For this we used the BIOLOV model that was validated in chemostat experiments.

It is worth noting that even if both the Redfieldian and the Mechanistic model are comparable, the involved mechanisms are really different since in the Mechanistic model the algal physiology is taken into account especially by integrating the mechanisms of photoadaptation. As a consequence, the Mechanistic model needs 8 state variables ( 3 of them representing phytoplankton) and 33 parameters whereas the Redfieldian model needs 6 state variables (one of them being phytoplankton) and 28 parameters plus either the 20 parameters used to discretized the $\mathrm{C}$ :Chl ratio along depth or the 3 parameters used in the representation of the $\mathrm{C}: \mathrm{Chl}$ ratio as a function of light.

The first conclusion of our study was that the Mechanistic model reproduces the reference data in a comparable manner 


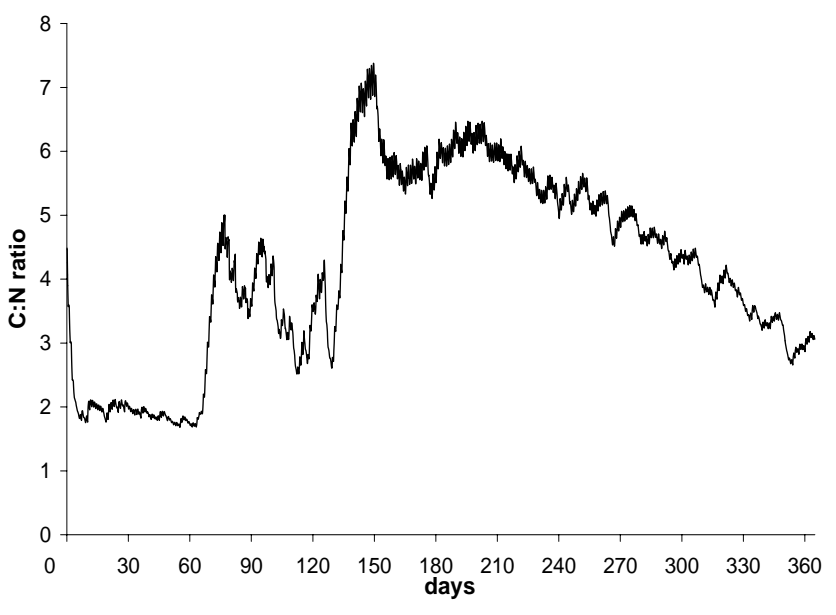

Fig. 17. Average $\mathrm{C}: \mathrm{N}$ ratio $(\mathrm{mgC} / \mathrm{mgN})$ over the 50 first meters of the water column computed with the Mechanistic model.

than the previous Redfieldian model. Both fluxes and stocks can be equally well predicted by both models.

However if the models are coinciding on an average basis, they are diverging from a variability prediction point of view. In the Mechanistic model biology adapts much faster to its environment giving rise to higher short term variations and finally to a higher variability.

As we have shown with e.g. C:Chl ratio versus light intensity the average model predictions remain in line with other empirical formulations.

At this point it can appear rather surprising that both simple and complicated model can reproduce accurate average fluxes. Of course the benefit of the mechanical more complex model is to provide a thinner time resolution of the phenomena.

The second and main conclusion of this paper is that the seasonal variability which appears in the $\mathrm{C}: \mathrm{N}$ ratio computed with the Mechanistic model and in the total production flux expressed in carbon unit is in line with previous experimental studies (Körtzinger et al., 2001). For an annual carbon production value similar to the one given by the Redfieldian model, the Mechanistic model gives higher production values in summer than the Redfieldian model. According to this point the Mechanistic model is better than the Redfieldian model since it was remarked in Mémery et al. (2002) that this latter gave too low carbon production estimates in summer.

Two points need to be addressed in future studies. First the proposed Mechanistic model has to be confronted to an independent data set from another period or another station, in order to fully assess its prediction capability. Second, the question of a possible higher variability on the variables and fluxes needs to be investigated further, and especially the possible implications on carbon cycle modelling studies as well as on sampling strategies and data interpretation.

Edited by: F. G. Schmitt

Reviewed by: T. Neumann and another referee

\section{References}

Andersen, V. and Prieur, L.: One-month study in the open NW Mediterranean Sea (DYNAPROC experiment, May 1995): overview of the hydrobiologeochemical structures and effects of wind events, Deep-Sea Research I, 47, 397-422, 2000.

Baumert, H.: On the theory of P-I curves, growth and light-dark adaptation in phytoplankton. Part I: constant temperature, Int. Rev. Ges. Hydrobiol., 81, 109-139, 1996.

Bury, S., Boyd, P., Preston, T., Savidge, G., and Owens, N.: Sizefractionated primary production and nitrogen uptake during a North Atlantic phytoplankton bloom: implications for carbon export estimates, Deep-Sea Research I, 48, 689-720, 2001.

Chalup, M. and Laws, E.: A test of the assumptions and predictions of recent microalgal growth models with the marine phytoplankter, Pavlova Luthri. Limnol. Oceanogr., 35, 583-596, 1990.

Cullen, J.: On models of growth and photosynthesis in phytoplankton, Deep-Sea Research, 37, 667-683, 1990.

Doney, S., Glover, D., and Najjar, R.: A new coupled, one-dimensional biological-physical model for the upper ocean:Applications to the JGOFS Bermuda Atlantic Time-series Study (BATS) site, Deep-Sea Research II, 43, 591-624, 1996.

Droop, M.: Vitamin B12 and marine ecology. IV. The kinetics of uptake growth and inhibition in Monochrysis lutheri, J. Mar. Bio. Ass. U.K., 48, 689-733, 1968.

Fasham, M., Ducklow, H., and McKelvie, S.: A nitrogenbased model of plankton dynamics in the oceanic mixed-layer, J. Mar. Res., 48, 591-639, 1990.

Faugeras, B., Lévy, M., Mémery, L., Verron, J., Blum, J., and Charpentier, I.: Can biogeochemical fluxes be recovered from nitrate and chlorophyll data? A case study assimilating data in the Northwestern Mediterranean Sea at the JGOFS-DYFAMED station, J. Mar. Sys., 40-41, 99-125, 2003.

Faure, C. and Papegay, Y.: Odyssée Version 1.6, the language reference manual, Rapport Technique 211, INRIA, 1997.

Flynn, K.: A mechanistic model for describing dynamic multinutrient, light, temperature interactions in phytoplankton, J. Plankton Res., 23, 977-997, 2001.

Gaspar, P., Gregories, Y., and Lefevre, J.: A simple eddy kinetic energy model for simulations of the oceanic vertical mixing: tests at station Papa and long term upper ocean study site, Journal of Geophysical Research, 95, 16 179-16 193, 1990.

Geider, R., MacIntyre, H., and Kana, T.: Dynamic model of phytoplankton growth and acclimation: responses of the balanced growth rate and the chlorophyll a:carbon ratio to light, nutrientlimitation and temperature, MEPS, 148, 187-200, 1997.

Geider, R., MacIntyre, H., and Kana, T.: A dynamic regulatory model of phytoplanktonic acclimatation to light, nutrients and temperature, Limnol. Oceanogr., 43, 679-694, 1998.

Gilbert, J. and Lemaréchal, C.: Some numerical experiments with variable storage quasi-Newton algorithms, Mathematical Programming, 45, 407-435, 1989.

Griewank, A.: Evaluating Derivatives. Principles and Techniques of Algorithmic Differentiation, Frontiers in applied mathematics, SIAM, 2000

Hood, E. M. and Merlivat, L.: Annual to interannual variations of $\mathrm{fCO}_{2}$ in the northwestern Mediterranean Sea: results from hourly measurements made by CARIOCA buoys, 1995-1997, J. Mar. Res., 59, 113-131, 2001.

Hurtt, G. and Armstrong, R.: A pelagic ecosystem model calibrated with BATS data, Deep-Sea Research II, 43, 653-683, 1996.

Körtzinger, A., Koeve, W., Kähler, P., and Mintrop, L.: C:N ratios 
in the mixed layer during the productive season in the northeast Atlantic Ocean, Deep-Sea Research I, 48, 661-688, 2001.

Lawson, L., Spitz, Y., Hofmann, E., and Long, R.: A data assimilation technique applied to a predator-prey model, Bulletin of Mathematical Biology, 57, 593-617, 1995.

Lefevre, N., Taylor, A., Gilbert, F., and Geider, R.: Modeling carbon to nitrogen and carbon to chlorophyll a ratios in the ocean at low latitudes: Evaluation of the role of physiological plasticity, Limnol. Oceanogr., 48, 1796-1807, 2003.

Lévy, M., Mémery, L., and André, J.-M.: Simulation of primary production and export fluxes in the Northwestern Mediterranean Sea, J. Mar. Res., 56, 197-238, 1998.

Martin, J. and Fitzwater, S.: Dissolved Organic Carbon in the Atlantic, Southern and Pacific Oceans, Nat., 356, 699-700, 1992.

Marty, J.: Opération DYFAMED, rapport d'activité pour 1993 et programme pour 1994, Tech. rep., programme France/JGOFS, 1993.

Mémery, L., Lévy, M., Vérant, S., and Mervilat, L.: The relevant time scales in estimating the air - sea $\mathrm{CO}_{2}$ exchange in a mid latitude region, Deep-Sea Research II, 49, 2067-2092, 2002.

Morel, A.: Optical modeling of the upper ocean in relation to its biogenous matter content (case I waters), Journal of Geophysical Research, 93, 10 749-10 768, 1988.
Pawlowski, L.: Modélisation de l'incorporation du carbone photosynthétique en environnement marin piloté par ordinateur, Phd thesis, Université P.M. Curie, Paris, 175 p, 2004.

Pawlowski, L., Bernard, O., Le Floc'h, E., and Sciandra, A.: Qualitative Behaviour of a phytoplankton growth model in a photobioreactor, in Proceedings of the 15th IFAC World Congress, Barcelona, Spain, 6 p, 2002.

Rhee, G. and Gothan, I.: The effect of environmental factors on phytoplankton growth: light and the interactions of light with nitrate limitation, Limnol. Oceanogr., 26, 649-659, 1981.

Sciandra, A., Gostan, J., Collos, Y., Descolas-Gros, C., Leboulanger, C., Martin-Jézéquiel, V., Denis, M., Lefèvre, D., Copin-Montégut, C., and Avril, B.: Growth compensating phenomena in continuous cultures of Dunaliella tertiolecta limited simultaneously by light and nitrate, Limnol. Oceanogr., 42, 1325-1339, 1997.

Sciandra, A., Lazzara, L., Claustre, H., and Babin, M.: Responses of the growth rate, pigment composition and optical properties of Cryptomonas sp. to light and nitrogen stresses, MEPS, 201, 107-120, 2000.

Spitz, Y., Moisan, J., and Abbot, M.: Configuring an ecosystem model using data from the Bermuda Atlantic Series (BATS), Deep-Sea Research II, 48, 1733-1768, 2001.

Zonneveld, C.: Light-limited microalgal growth: a comparison of modelling approaches, Ecological Modelling, 113, 41-54, 1998. 